\title{
Abatement of Toluene Using a Sequential Adsorption-Catalytic Oxidation Process: Comparative Study of Potential Adsorbent/Catalytic Materials
}

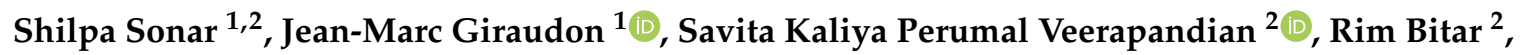 \\ Karen Leus ${ }^{3}$, Pascal Van Der Voort ${ }^{3}{ }^{(0)}$, Jean-François Lamonier ${ }^{1}{ }^{(1)}$, Rino Morent ${ }^{2}$, \\ Nathalie De Geyter ${ }^{2}$ (D) and Axel Löfberg ${ }^{1, *}$ (i) \\ 1 Univ. Lille, CNRS, Centrale Lille, Univ. Artois, UMR 8181-UCCS-Unité de Catalyse et Chimie du Solide, \\ F-59000 Lille, France; shilpasonar01@gmail.com (S.S.); jean-marc.giraudon@univ-lille.fr (J.-M.G.); \\ jean-francois.lamonier@univ-lille.fr (J.-F.L.) \\ 2 Research Unit Plasma Technology, Department of Applied Physics, Faculty of Engineering and Architecture, \\ Ghent University, Sint-Pietersnieuwstraat 41 (B4), 9000 Ghent, Belgium; \\ Savita.KaliyaPerumalVeerapandian@ugent.be (S.K.P.V.); Rim.Bitar@UGent.be (R.B.); \\ Rino.Morent@UGent.be (R.M.); Nathalie.DeGeyter@UGent.be (N.D.G.) \\ 3 Center for Ordered Materials, Organometallics and Catalysis (COMOC), Department of Chemistry, \\ Faculty of Sciences, Ghent University, Krijgslaan 281 (S3), 9000 Ghent, Belgium; Karen.Leus@ugent.be (K.L.); \\ pascal.vandervoort@ugent.be (P.V.D.V.) \\ * Correspondence: axel.lofberg@univ-lille.fr
}

Received: 12 June 2020; Accepted: 30 June 2020; Published: 8 July 2020

\begin{abstract}
A novel strategy for toluene abatement was investigated using a sequential adsorption-regeneration process. Commercial Hopcalite $\left(\mathrm{CuMn}_{2} \mathrm{O}_{x}\right.$, Purelyst101MD), Ceria nanorods, and $\mathrm{UiO}-66-\mathrm{SO}_{3} \mathrm{H}$, a metal-organic framework (MOF), were selected for this study. Toluene was first adsorbed on the material and a mild thermal activation was performed afterwards in order to oxidize toluene into $\mathrm{CO}_{2}$ and $\mathrm{H}_{2} \mathrm{O}$. The materials were characterized by $\mathrm{XRD}, \mathrm{N}_{2}$ adsorption-desorption analysis, $\mathrm{H}_{2}$-TPR and TGA/DSC. The best dynamic toluene adsorption capacity was observed for UiO-66- $\mathrm{SO}_{3} \mathrm{H}$ due to its hierarchical porosity and high specific surface area. However, in terms of balance between storage and catalytic properties, Hopcalite stands out from others owing to its superior textural/chemical properties promoting irreversible toluene adsorption and outstanding redox properties, allowing a high activity and $\mathrm{CO}_{2}$ selectivity in toluene oxidation. The high conversion of toluene into $\mathrm{CO}_{2}$ which easily desorbs from the surface during heating treatment shows that the sequential adsorption-catalytic thermal oxidation can encompass a classical oxidation process in terms of efficiency, $\mathrm{CO}_{2}$ yield, and energy-cost saving, providing that the bifunctional material displays a good stability in repetitive working conditions.
\end{abstract}

Keywords: adsorption; catalytic oxidation; sequential adsorption-thermal oxidation; toluene abatement; Hopcalite; nanorod Ceria; $\mathrm{UiO}-66-\mathrm{SO}_{3} \mathrm{H}$

\section{Introduction}

Volatile organic compounds (VOCs) usually refer to organic compounds with boiling points less than or equal to $250{ }^{\circ} \mathrm{C}$ at atmospheric pressure and high vapor pressures (above $0.1 \mathrm{~mm} \mathrm{Hg}$ ) at room temperature [1,2]. Among the different types of VOCs, aromatics play an important role in stratospheric ozone depletion as well as aerosol and smog formations [3] and have adverse effects on human health [3]. Toluene, which is an important representative of aromatic VOCs, is widely 
found in indoor and outdoor air due to its use as solvent. Owing to stringent legislations on VOC emissions, various technologies, such as adsorption [4,5], absorption [6], photocatalytic degradation [7], catalytic oxidation [5,8], and catalytic combustion [8], have been extensively used to scale down the energy cost [8].

For instance, storage regeneration processes have been proposed and investigated to eliminate low-concentration indoor VOCs such as formaldehyde and benzene [9]. This sequential method implies two steps: (i) first, the VOC is adsorbed on a material and (ii) then a regeneration of the material through VOC oxidation into $\mathrm{CO}_{2}$ and $\mathrm{H}_{2} \mathrm{O}$ is performed. A key issue in this approach is the design of adsorbent/catalytic materials which should possess balanced properties between storage and regeneration. The bifunctional materials used for the storage of VOCs should thus not only possess high and selective VOC storage capacity, but also be easily regenerated without any release of the VOCs or generation of secondary pollutants. To that order, thermal regeneration [9], non-thermal plasma oxidation [10,11], or ozone enabled regeneration [12] have been assessed as regeneration methods.

Regarding adsorption/catalytic regeneration, Guillemot et al. reported on a double adsorbent/catalyst bed for the removal of tetrachloroethylene (PCE) and methyl ethyl ketone (MEK) in a moist gas stream. The VOCs were physically adsorbed on an appropriate adsorbent (zeolites) at room temperature. After that, the VOCs were desorbed from the adsorbent and catalytically oxidized by supported catalysts ( $\mathrm{Pt}, \mathrm{Ag}$, etc.) at elevated temperature. It appeared that the adsorbent-catalyst couple remains efficient for MEK transformation during several successive adsorption/oxidation cycles [13].

In the present work, the sequential adsorption-catalytic process is proposed for the abatement of toluene as VOC. The implementation of such process requires to identify proper materials that exhibit both sufficient adsorption capacity and good catalytic performances. This can be approached by different ways, for example by adding catalytic functions to well-known adsorbents or by developing the adsorption properties of known catalytic materials. For instance, in this exploratory work, Hopcalite (Purelyst 101MD), nanorod Ceria, and a sulfonic Zr-based metal organic framework (MOF) $\left(\mathrm{UiO}-66-\mathrm{SO}_{3} \mathrm{H}\right)$ have been used for the adsorption-thermal catalytic removal of toluene using a mild thermal activation from $25^{\circ} \mathrm{C}$ up to $250^{\circ} \mathrm{C}$.

Hopcalite $\left(\mathrm{CuMnO}_{x}\right)$, a cost-effective catalyst, consists of a mixture of copper and manganese oxides [14]. It is recognized as one of the most efficient catalyst for low-temperature oxidation reactions such as CO oxidation [14], indoor HCHO oxidation [15], and VOC total oxidation. As a consequence, Hopcalite is widely used for respiratory protection systems for various types of applications like military, mining and space devices, etc. [16]. The high catalytic activity in $\mathrm{CO}$ oxidation over $\mathrm{CuMnO}_{x}$ catalyst has been ascribed previously to the redox reaction $\mathrm{Cu}^{2+}+\mathrm{Mn}^{3+} \rightleftharpoons \mathrm{Cu}^{+}+\mathrm{Mn}^{4+}$ and the high adsorption of $\mathrm{CO}$ onto $\mathrm{Cu}^{2+} / \mathrm{Mn}^{4+}$ and of $\mathrm{O}_{2}$ onto $\mathrm{Cu}^{+} / \mathrm{Mn}^{3+}$ [14]. It should be noted that the mesoporous $\mathrm{Cu}-\mathrm{Mn}$ Hopcalite catalyst is generally highly active in the amorphous state, but loses its catalytic activity at high temperature $\left(>500^{\circ} \mathrm{C}\right)$ owing to the generation of crystallized phase [14].

Cerium oxide $\left(\mathrm{CeO}_{2}\right)$ is widely investigated as a catalyst or catalyst support for various applications in the field of environmental catalysis, in particular three-way catalysis. Ceria nanoparticles (Ceria $\mathrm{NPs}$ ) have unique redox properties of easy cycling between the $\mathrm{Ce}^{4+}$ and $\mathrm{Ce}^{3+}$ oxidation states. As a consequence, the high oxygen storage/release capacity makes this material a key ingredient for catalytic oxidation reactions. The enhancement of defects linked to the morphology, size, and shape of cerium oxide is known to promote catalytic activity. In that respect, $\mathrm{NPs}$ of $\mathrm{CeO}_{2}$ nanorods (NR) exposing surface (110) and (100) planes exhibit enhanced catalytic properties in CO oxidation [17].

$\mathrm{UiO}-66-\mathrm{SO}_{3} \mathrm{H}$ (UiO: University of Oslo) is a metal organic frameworks (MOF) isostructural with UiO-66 and can be synthesized easily via a direct solvothermal approach [18]. MOFs exhibit tunable structures, large surface areas and multifunctional properties which have attracted increasing attention in various applications such as adsorption [19], catalytic oxidation [20,21], and photocatalysis [22]. MOFs might be considered as a potential alternative to zeolites and active carbons in adsorption 
technologies. UiO-66- $\mathrm{SO}_{3} \mathrm{H}$ is an acid MOF used in acid-basic reactions which also shows high performance in terms of $\mathrm{CO}_{2}$ adsorption capacity.

In the present paper, adsorption-desorption/oxidation of gaseous toluene on the two calcined materials (Hopcalite and $\mathrm{CeO}_{2}$ nanorods) and activated MOF was investigated by breakthrough experiments followed by toluene desorption experiments at ambient temperature to be ended by temperature programmed reactions (TPR). At that stage, the TP reactions were performed either in He to probe the redox properties of the materials or in a $\mathrm{He}_{2} \mathrm{O}_{2}$ (50:50) gaseous mixture to assess the catalytic properties of the materials during this regeneration step. In a complementary approach, the catalytic properties were investigated from light-off curves. Finally, the adsorbent/catalyst performance of the materials was assessed and discussed in accordance with their physico-chemical properties.

\section{Results and Discussion}

\subsection{Catalyst Characterization}

\subsubsection{Structural Properties}

The X-ray diffraction (XRD) pattern (Figure 1) of Hopcalite shows two low intensity peaks positioned at $36.7^{\circ}$ and $66.0^{\circ}$ in $2 \theta$ originating from some based $\mathrm{MnO}_{2}$ spacing in line with the amorphous character of the material [23]. The XRD pattern of the as-synthesized $\mathrm{CeO}_{2}-\mathrm{NR}$ shows well defined diffraction peaks located at $28.5^{\circ}, 33.1^{\circ}, 47.5^{\circ}, 56.3^{\circ}, 59.1^{\circ}, 69.4^{\circ}, 76.7^{\circ}$, and $79.1^{\circ}$ ascribed to the (111), (200), (220), (311), (222), (400), (331), and (420) planes of the face-centered cubic (fcc) $\mathrm{CeO}_{2}$ fluorite structure (JCPDS 34-0394, space group Fm3m) [24]. Using the Scherrer formula, it was found that mean crystallite size of $8 \mathrm{~nm}$ from the (111) peak. The $\mathrm{XRD}$ pattern of $\mathrm{UiO}-66-\mathrm{SO}_{3} \mathrm{H}$ is in good agreement with those reported previously for a crystalline activated $\mathrm{UiO}-66-\mathrm{SO}_{3} \mathrm{H}[18,25-27]$.

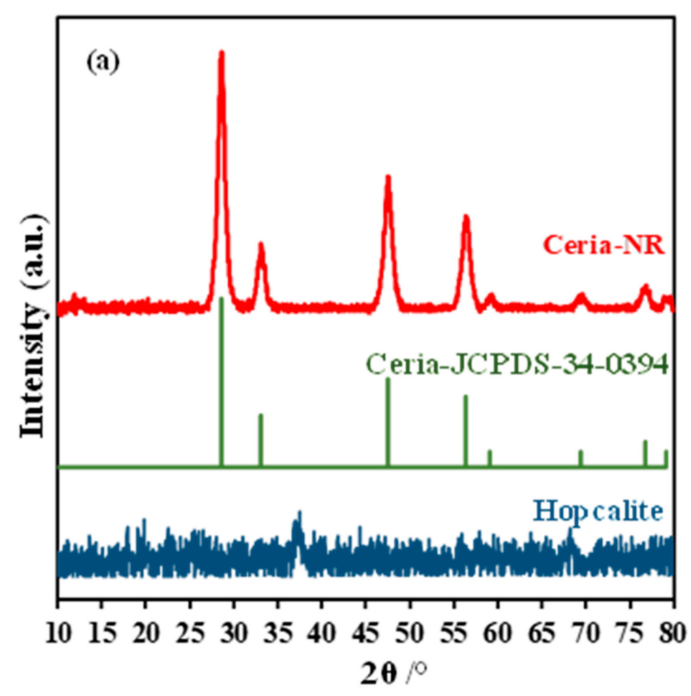

Figure 1. Cont. 


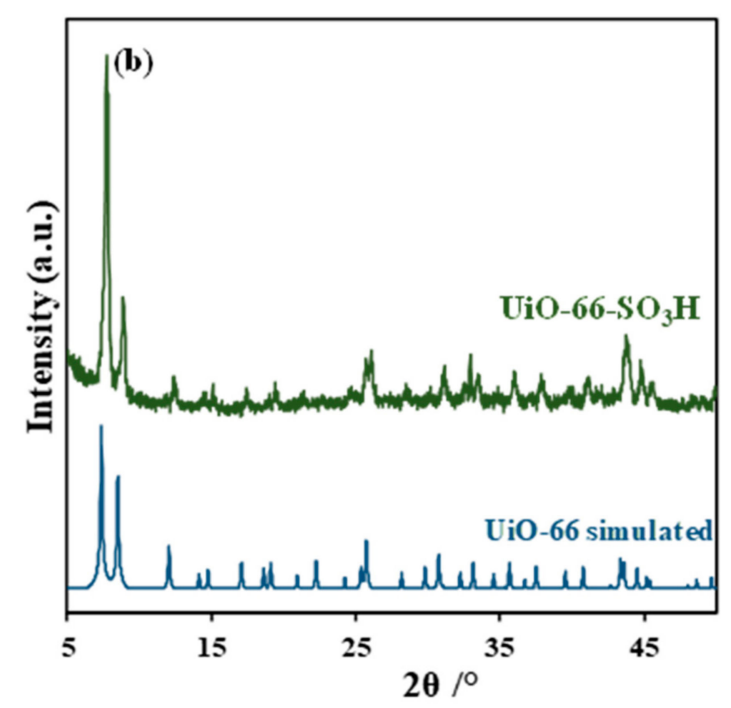

Figure 1. XRD patterns of (a): Hopcalite and $\mathrm{CeO}_{2}-\mathrm{NR}$, (b): $\mathrm{UiO}-66-\mathrm{SO}_{3} \mathrm{H}$.

\subsubsection{Textural Properties}

The $\mathrm{N}_{2}$ adsorption-desorption isotherms and pore size distribution (PSD; insets) of the three materials are illustrated in Figure 2 and the corresponding textural properties are summarized in Table 1. The crushed and sieved particles of commercial Hopcalite show a type IV isotherm with an $\mathrm{H} 3$ hysteresis loop in the relative pressure $\left(\mathrm{P} / \mathrm{P}_{0}\right)$ range of $0.42-1.0$. The formation of two adsorption steps at relative pressures $\left(\mathrm{P} / \mathrm{P}_{0}\right) 0.6-0.8$ and $0.9-1.0$ due to capillary condensation is indicative of a mesoporous material in line with well-distributed pore diameters at $7.8 \mathrm{~nm}$ followed by a broad porosity distribution displaying maximum pore diameters around $80 \mathrm{~nm}$. Additionally, the vertical nitrogen uptake at $\mathrm{P} / \mathrm{P}_{0}$ below 0.05 is characteristic of micropore filling. The specific surface area is $229 \mathrm{~m}^{2} \mathrm{~g}^{-1}$ and the total pore volume $\mathrm{V}_{\mathrm{p}}$ is $0.45 \mathrm{~cm}^{3} \mathrm{~g}^{-1}$. The $S_{\text {BET }}$ value is less than the one reported by the supplier $\left(>300 \mathrm{~m}^{2} / \mathrm{g}\right.$ as pellets).

The isotherm of Ceria-NR shows a Type IV shape with a Type H1 hysteresis loop in the high relative pressure $\left(\mathrm{P} / \mathrm{P}_{0}\right)$ range of $0.82-1.0$. The $\mathrm{PSD}$ shows a broad peak centered at $35 \mathrm{~nm}$ corresponding to the inter-particle spaces in the scaffold-like assembly of nanorods [28]. The BET surface area of $91 \mathrm{~m}^{2} \mathrm{~g}^{-1}$ and $\mathrm{Vp}$ of $0.63 \mathrm{~cm}^{3} \mathrm{~g}^{-1}$ are in accordance with previous results $[29,30]$.

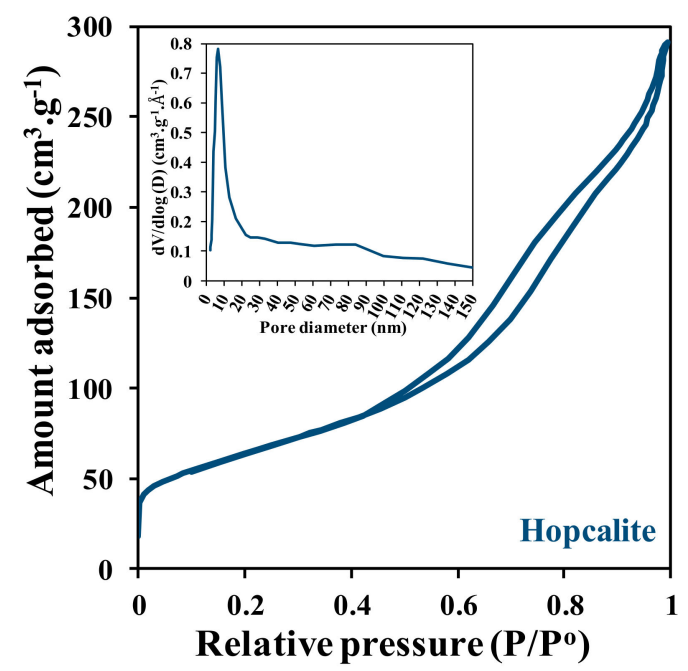

Figure 2. Cont. 

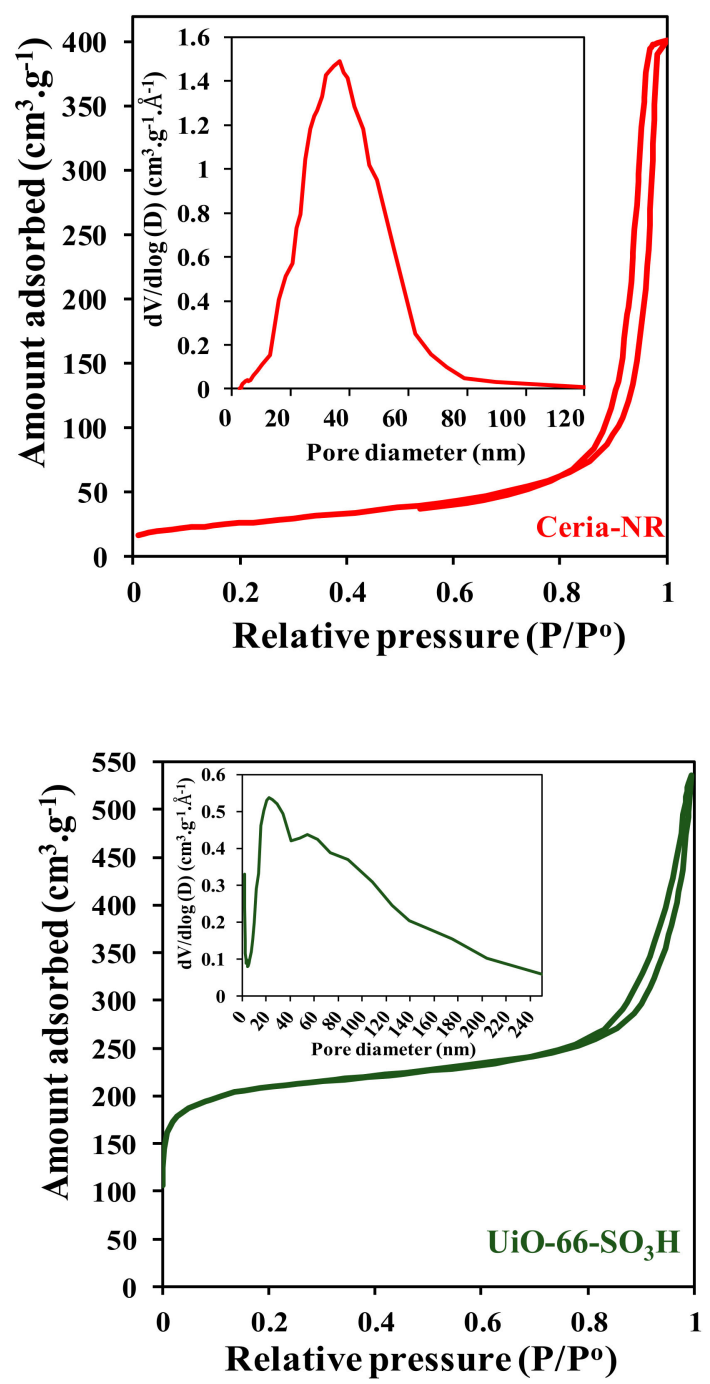

Figure 2. $\mathrm{N}_{2}$ adsorption/desorption isotherms and PSD (inserts) of Hopcalite, Ceria-NR and $\mathrm{UiO}-66-\mathrm{SO}_{3} \mathrm{H}$.

Table 1. Textural and redox properties of the materials.

\begin{tabular}{cccc}
\hline Materials & $\begin{array}{c}\mathbf{S}_{\text {BET }} \\
\left(\mathbf{m}^{\mathbf{2}} \mathbf{g}^{\mathbf{1}}\right)\end{array}$ & $\mathbf{V}_{\mathbf{p}} \mathbf{a}^{\mathbf{(}} \mathbf{c m}^{\mathbf{3}} \mathbf{g}^{-\mathbf{1})}$ & $\mathbf{H}_{\mathbf{2}}$ Consumption $\left(\mathbf{m m o l} \mathbf{~ g}^{\mathbf{1})}\right.$ \\
\hline Hopcalite & 229 & 0.45 & 11.1 \\
Ceria-NR & 91 & 0.63 & 0.65 \\
$\mathrm{UiO}-66-\mathrm{SO}_{3} \mathrm{H}$ & 685 & 0.82 & 0.60 \\
\hline
\end{tabular}

a Total pore volume.

The $\mathrm{N}_{2}$ sorption isotherm of activated $\mathrm{UiO}-66-\mathrm{SO}_{3} \mathrm{H}$ is a somewhat mixed type $\mathrm{I} / \mathrm{IV}$, with a sharp increase of gas uptake at the low-pressure range and an observable hysteresis between adsorption and desorption branches in the high relative pressure $\left(\mathrm{P} / \mathrm{P}_{0}\right)$ range of $0.73-1.0$. $\mathrm{UiO}-66-\mathrm{SO}_{3} \mathrm{H}$ is a microporous metal-organic framework. The lattice capillary condensation is due to interparticle porosity. As formic acid acts primarily as a monodentate modulator to compete with bidentate bridging $\mathrm{H}_{2} \mathrm{BDC}-\mathrm{SO}_{3} \mathrm{H}$ ligands for coordination sites on $\mathrm{Zr}$-oxo clusters, the generation of missing-linker defects can be envisioned via incomplete exchange of the pre-loaded formate ligands on the $\left[\mathrm{Zr}_{6} \mathrm{O}_{4}(\mathrm{OH})_{4}\right]^{12+}$ secondary building units [31]. The specific surface area of $685 \mathrm{~m}^{2} \mathrm{~g}^{-1}$ is in agreement with values generally reported for a rather similar material $[18,32,33]$ although an exceeding value of about 
$1180 \mathrm{~m}^{2} / \mathrm{g}$ was reported for a sulfonic UiO-66 synthesized via a direct solvothermal approach using a mixture of organic linkers $\left(\mathrm{H}_{2} \mathrm{BDC}-\mathrm{SO}_{3} \mathrm{H} / \mathrm{H}_{2} \mathrm{BDC}\right)$ [34].

To sum up, the textural properties are broadly in line with those expected for commercial Hopcalite, $\mathrm{CeO}_{2}-\mathrm{NR}$ and $\mathrm{UiO}-66-\mathrm{SO}_{3} \mathrm{H}$ taking into account the adopted experimental procedures. UiO-66- $\mathrm{SO}_{3} \mathrm{H}$ shows an outstanding $S_{\mathrm{BET}}$ value as compared to the two other porous materials. Additionally, the three materials differ from their pore size distributions. Indeed, the functionalized $\mathrm{UiO} 66-\mathrm{SO}_{3} \mathrm{H}$ displays a hierarchical porosity while the two other solids are mesoporous with Hopcalite developing smaller pores than $\mathrm{CeO}_{2}-\mathrm{NR}$.

\subsubsection{Redox Properties}

The redox properties of the samples were assessed by means of $\mathrm{H}_{2}$-TPR experiments. $\mathrm{H}_{2}$-consumption traces are reported in Figure 3 and $\mathrm{H}_{2}$ consumption amounts are compiled in Table 1.
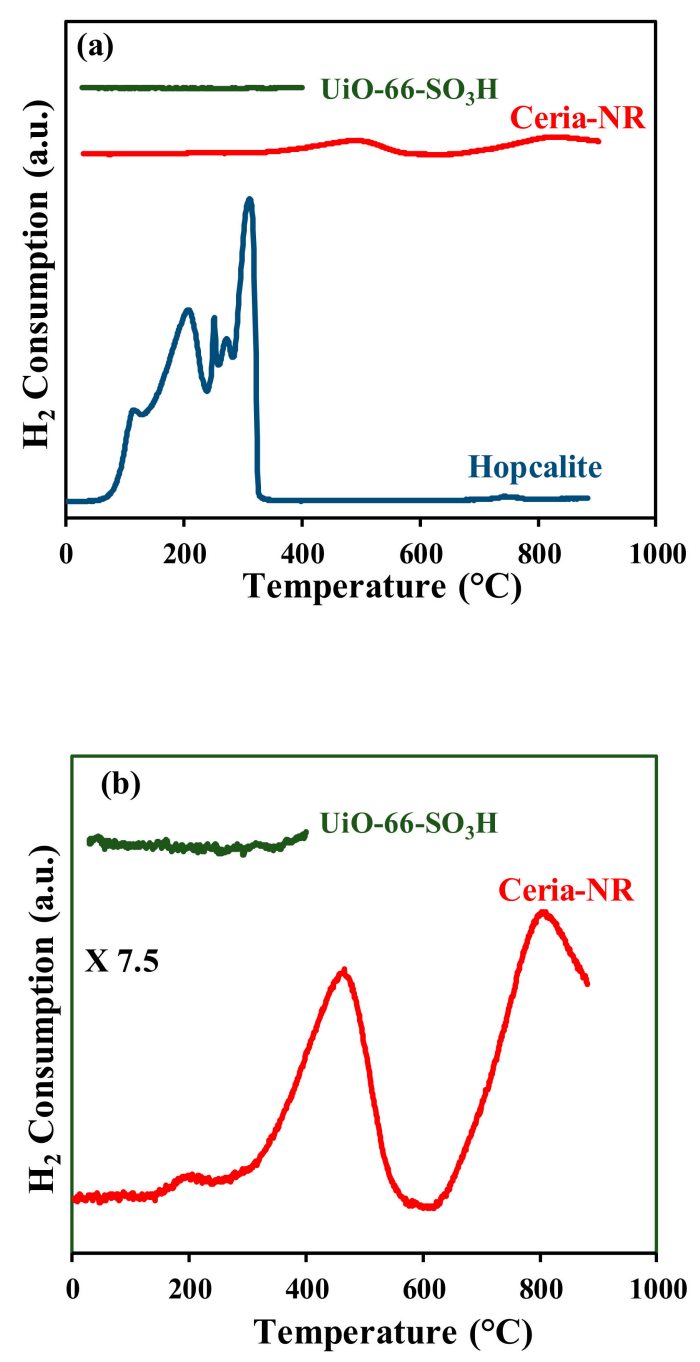

Figure 3. (a) $\mathrm{H}_{2}$-TPR curves of the samples; (b) zoom of the $\mathrm{H}_{2}$-TPR curves.

The $\mathrm{H}_{2}$ consumption trace of commercial Hopcalite is complex and resembles broadly to that reported previously for a CuO- $\mathrm{MnO}_{2}$ solid [35]. The reduction process starts at $90{ }^{\circ} \mathrm{C}$ and ends at approximately $360^{\circ} \mathrm{C}$. Five reduction peaks are observed with maxima located at 147, 209, 239, 273 and $343{ }^{\circ} \mathrm{C}$. The first peak at $110{ }^{\circ} \mathrm{C}$ and part of the second one are assigned to the reduction of $\mathrm{CuO}_{x}$ entities into $\mathrm{Cu}(0)$. As soon as $\mathrm{Cu}(\mathrm{II})$ is reduced into $\mathrm{Cu}(0)$, a spill-over of hydrogen takes place from $\mathrm{Cu}(0)$ to $\mathrm{Mn}(\mathrm{IV})$ entities. As that stage, the reduction of $\mathrm{Mn}(\mathrm{IV})$ species occurs in different steps to give 
$\mathrm{MnO}$ at the end of the process. This is supported by the quantitative results of the $\mathrm{H}_{2}$ consumption per gram of catalyst. The $\mathrm{H}_{2}$ consumption of $11.1 \mathrm{mmol} \mathrm{g}^{-1}$ results to a Mn average oxidation state (AOS) of 3.92, a value close to 4.0, assuming the complete reduction of $\mathrm{CuO}$ into $\mathrm{Cu}(0)$.

The $\mathrm{H}_{2}$-TPR trace is very flat for $\mathrm{CeO}_{2}-\mathrm{NR}$ attesting of a low $\mathrm{H}_{2}$ consumption as compared with Hopcalite. Three reduction peaks centered at $221{ }^{\circ} \mathrm{C}, 488^{\circ} \mathrm{C}$ and $830^{\circ} \mathrm{C}$ related to surface-adsorbed oxygen, sub-surface oxygen and bulk oxygen can be detected in Figure 3b [36]. The sub-surface oxygen species, which are generally considered as the active oxygen species in the low temperature oxidation reactions, amount to $0.65 \mathrm{mmol} / \mathrm{g}_{\text {cat }}$, which is much less than the value of $1.05 \mathrm{mmol} / \mathrm{g}_{\text {cat }}$ obtained by $\mathrm{Z}$. Hu et al. for Ceria nanorods [17]. The $\mathrm{H}_{2}-\mathrm{TPR}$ trace for $\mathrm{UiO}-66-\mathrm{SO}_{3} \mathrm{H}$ is flat from $20{ }^{\circ} \mathrm{C}$ to about $400{ }^{\circ} \mathrm{C}$ in line with a non-redox active material.

XPS has been performed on Hopcalite to get information about the composition and chemical states of $\mathrm{Cu}$ and $\mathrm{Mn}$. The atomic $\mathrm{Cu} / \mathrm{Mn}$ ratio is 0.16 . The $\mathrm{Mn}$ AOS, estimated from BE energy separation of the two Mn 3s peaks [37], is 3.14. The BE of $\mathrm{Cu} 2 \mathrm{p}_{3 / 2}$ of $933.3 \mathrm{eV}$ is in accordance with $\mathrm{Cu}$ (II) oxide related species [38]. Hence, we get a $\mathrm{Cu}(\mathrm{II}) / \mathrm{Mn}$ (III) redox system at the surface of Hopcalite in accordance with literature [39].

\subsubsection{Thermal Stabilities Properties}

The thermal stability of the solids has been assessed through TGA/DSC characterizations performed in dry air (Figure 4).

For the activated UiO-66- $\mathrm{SO}_{3} \mathrm{H}$, the DTG curve shows minima at $185^{\circ} \mathrm{C}$ and $520^{\circ} \mathrm{C}$ indicative of two main weight loss steps (Figure 4). The first weight loss ( $\approx 20 \mathrm{wt} \%)$ up to $300{ }^{\circ} \mathrm{C}$ can be attributed to the release of volatile impurities and $\mathrm{CO}_{2}$ trapped in the porous network of the MOF [18]. This assumption is supported by the fact that $\mathrm{UiO}-66-\mathrm{SO}_{3} \mathrm{H}$ loses $11.6 \mathrm{wt} \%$ after being heated at $100{ }^{\circ} \mathrm{C}$ under vacuum prior to the $\mathrm{N}_{2}$ adsorption measurement and that no heat flow is detected for a temperature up to $400{ }^{\circ} \mathrm{C}$. A small weight loss occurs between 300 and $400{ }^{\circ} \mathrm{C}(\approx 4 \mathrm{wt} \%)$. The second main weight loss in the $400-700^{\circ} \mathrm{C}$ temperature range amounting to $41 \mathrm{wt} \%$ is due to the decomposition of the MOF. A strong exothermic peak at $520^{\circ} \mathrm{C}$ substantiates such a thermal decomposition. The weight loss of $41 \mathrm{wt} \%$ is substantially less than the expected one of $65.5 \mathrm{wt} \%$ assuming total decomposition of $\left[\mathrm{Zr}_{6} \mathrm{O}_{4}(\mathrm{OH})_{4}\left(\mathrm{BDC}-\mathrm{SO}_{3} \mathrm{H}\right)_{6}\right]$ into $\mathrm{ZrO}_{2}$. This can be related to partial substitution of the bridging $\mathrm{BDC}-\mathrm{SO}_{3} \mathrm{H}$ linkers for formate ligands [40].

Hence it can be stated from TG analysis coupled with DSC that the three samples under study can accommodate a thermal activation at $250{ }^{\circ} \mathrm{C}$ without deterioration which is a prerequisite for the intended regeneration process.
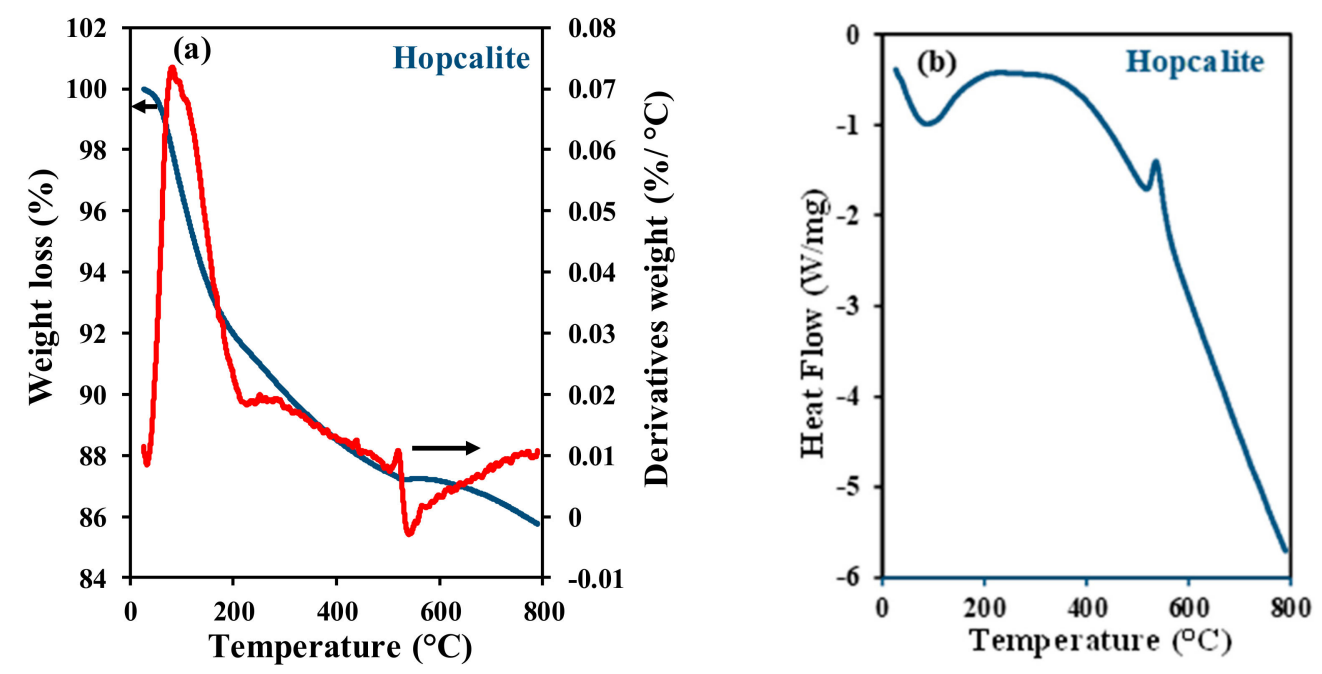

Figure 4. Cont. 

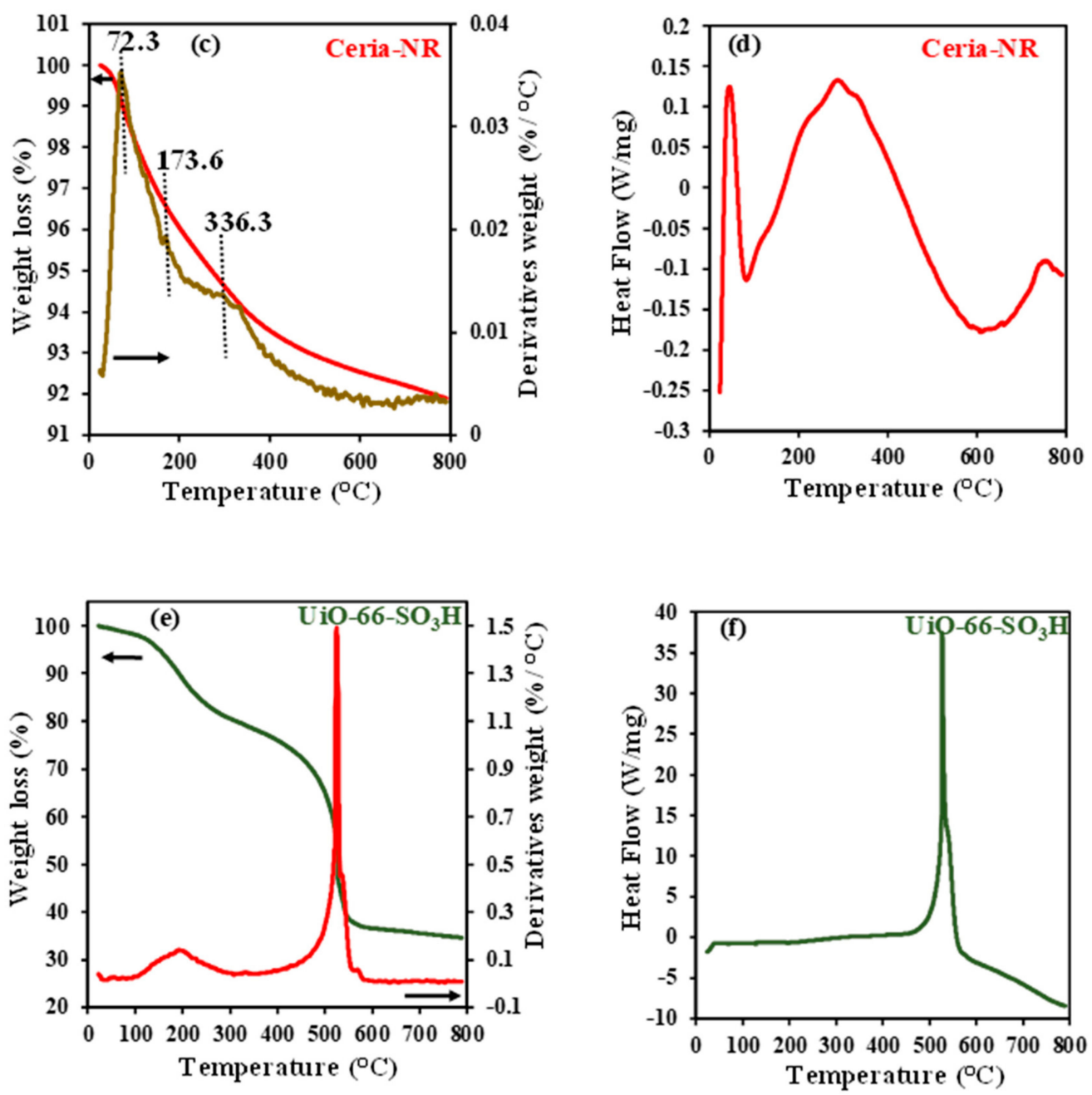

Figure 4. Weight loss $(\mathbf{a}, \mathbf{c}, \mathbf{d})$ and heat flow $(\mathbf{b}, \mathbf{e}, \mathbf{f})$ profiles during TGA-DTG analysis of Hopcalite $(\mathbf{a}, \mathbf{b})$, $\mathrm{CeO}_{2}-\mathrm{NR}(\mathbf{c}, \mathbf{d})$ and $\mathrm{UiO}-66-\mathrm{SO}_{3} \mathrm{H}(\mathbf{e}, \mathbf{f})$.

\subsection{Catalytic Oxidation of Toluene}

The light-off curves for toluene oxidation are shown in Figure 5 and the $T_{10}, T_{50}$, and $T_{90}$ (temperatures required to achieve $10 \%, 50 \%$, and $90 \%$ of toluene conversion into $\mathrm{CO}_{2}$ ) are given in Table 2. During the light-off curve study, only $\mathrm{CO}_{2}$ and $\mathrm{H}_{2} \mathrm{O}$ products have been observed.

Table 2. Catalytic properties of the solids in the toluene oxidation.

\begin{tabular}{cccc}
\hline Catalyst & $\mathbf{T}_{\mathbf{1 0}}\left({ }^{\circ} \mathbf{C}\right)$ & $\mathbf{T}_{\mathbf{5 0}}\left({ }^{\circ} \mathbf{C}\right)$ & $\mathbf{T}_{\mathbf{9 0}}\left({ }^{\circ} \mathbf{C}\right)$ \\
\hline Hopcalite & 157 & 185 & 291 \\
Ceria-NR & 232 & 321 & - \\
UiO-66-SO $\mathrm{SO}_{3} \mathrm{H}$ & - & - & - \\
\hline
\end{tabular}

Among the different materials, Hopcalite exhibits the best specific activity in terms of $\mathrm{T}_{10}, \mathrm{~T}_{50}$ and $\mathrm{T}_{90}$. Such results are in accordance with those reported elsewhere [41]. The textural properties (mesoporosity, amorphous state) coupled to the easy cycling between $\mathrm{Mn}$ and $\mathrm{Cu}$ different valences account for such a behavior. $\mathrm{CeO}_{2}-\mathrm{NR}$ is significantly less active as $\mathrm{T}_{90}$ could not be measured $\left(>330^{\circ} \mathrm{C}\right)$ and the $\mathrm{T}_{50}$ of $321^{\circ} \mathrm{C}$ is substantially higher than that of Hopcalite. However, Ceria itself is sufficiently active to catalyze the oxidation of toluene. The numerous defects in Ceria in the form of oxygen vacancies are believed to be responsible for its unique catalytic properties. Indeed, Ceria with NR morphology is generally recognized to promote oxygen vacancies. However, the surface oxygen 
amount of $0.65 \mathrm{mmol} \mathrm{g}_{\mathrm{cat}}{ }^{-1}$ is two times less than the amount found by Hu et al. [17]. As described by López et al. [42], the prevalence of surface oxygen vacancies (linked to a high surface-to-bulk oxygen ratio) promotes the activity of the catalysts. Consequently, the lower amount of surface Ceria may account herein for a $\mathrm{T}_{50}$ value higher than reported in the literature for NR Ceria, which are typically in the order of $210-220^{\circ} \mathrm{C}$ [42]. As expected, UiO-66- $\mathrm{SO}_{3} \mathrm{H}$ does not convert toluene due to a lack of redox properties. Taking into account the carbon balance, it is found that toluene is trapped inside the UiO66- $\mathrm{SO}_{3} \mathrm{H}$ structure.

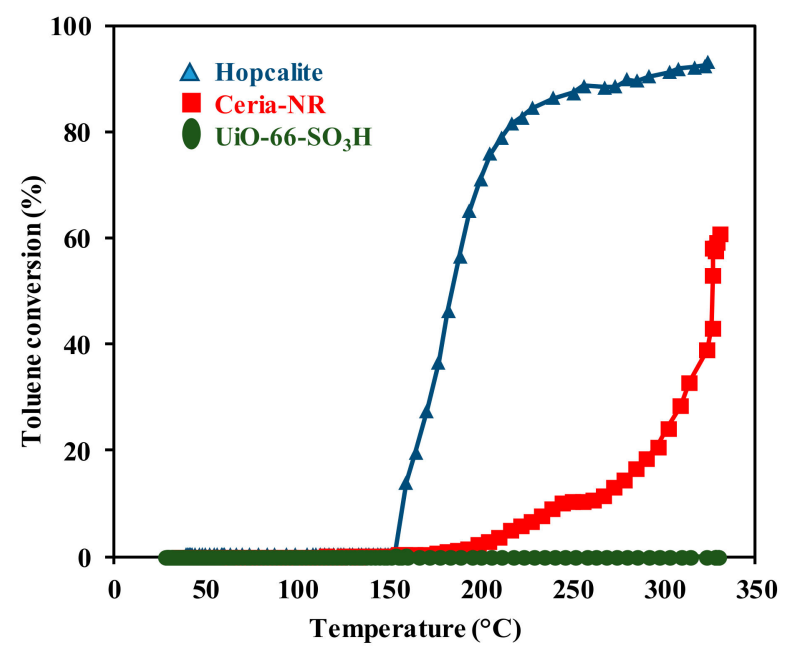

Figure 5. Light-off curves obtained in the presence of Hopcalite, Ceria-NR and $\mathrm{UiO}-66-\mathrm{SO}_{3} \mathrm{H}$ for toluene oxidation.

\subsection{Sequential Adsorption/Thermal Conversion}

\subsubsection{Effect of the Initial Toluene Concentration on Hopcalite}

To investigate the dynamic adsorption behavior of toluene over Hopcalite, breakthrough adsorption tests were performed with different initial concentrations of toluene (Figure 6a) ranging from 50 to $500 \mathrm{ppm}$. The adsorption process consists of three steps. First, toluene is fully adsorbed by Hopcalite and very low concentrations of toluene are detected at the outlet of the reactor. This is generally called the unsaturated zone of the breakthrough curve. Second, the appearance of non-adsorbed toluene in the outlet flow, described as the breakthrough stage, is indicative of a weaker adsorption of toluene and by mass transfer limitations. Finally, the inlet toluene concentration is reached, which indicates the saturation [43] and allows for the evaluation of dynamic toluene adsorption capacity of Hopcalite in the given conditions.

At high concentrations of toluene (200 and 500 ppm), the adsorption of toluene is fast. The time during which total adsorption occurs (unsaturated zone) is very short and does not significantly depend on toluene inlet concentration. The curves mostly differentiate by the slope at which saturation is reached in the breakthrough stage. The total adsorption capacity is very similar, in the range of approximately $380-390 \mu \mathrm{mol} \mathrm{g}^{-1}$ (Table 3). This behavior may be due to the improvement of driving force for mass transfer across the liquid film along with increasing of the adsorption rate which leads to quick saturation of the adsorbent [44]. This is even more enhanced when $100 \mathrm{ppm}$ toluene feed is used for which the unsaturated zone is less well defined and the adsorption process slower. Finally, with $50 \mathrm{ppm}$ toluene feed, the process is radically different as no toluene can be detected for a long period and subsequently the saturation abruptly occurs.

The different behavior during the toluene adsorption step according to inlet concentration also affects the "useful" adsorption capacity of the material. Indeed, in a real abatement process, the outlet toluene concentration would not be allowed to exceed a given threshold value, i.e., the adsorption step would need to be stopped once the threshold is reached. If one arbitrarily sets the threshold at $10 \mathrm{ppm}$, 
the breakthrough curves allow to determine approximately the useful adsorption capacity at 470, 230, 160 and $190 \mu \mathrm{mol} \mathrm{g}^{-1}$ with initial toluene concentrations of 50, 100, 200, and $500 \mathrm{ppm}$, respectively. With the exception of $50 \mathrm{ppm}$ conditions, these values are significantly lower than those obtained when the full adsorption capacity is considered (Table 3). This suggests that Hopcalite materials should be used preferentially in abatement processes involving rather low toluene concentrations.

These results suggest a complex adsorption process which could involve a rapid adsorption and condensation in the macropores of Hopcalite at high toluene feed concentration followed by diffusion in the mesopores of the solid (Figure 6a). At lower toluene feed concentration, adsorption can occur directly inside the mesoporous structure. Differences can also be seen in the desorption of toluene both at room temperature (not represented) and during heating (Figure 6b) in helium. Above $200 \mathrm{ppm}$ toluene concentration, considerable amounts of toluene $\left(72-74 \mu \mathrm{mol} \mathrm{g}{ }^{-1}\right)$ desorb at room temperature, showing that adsorption is strongly reversible. Using $100 \mathrm{ppm}$, this amount reduces to approx. $38 \mu \mathrm{mol} \mathrm{g}^{-1}$ but a higher amount of toluene desorbs during the heating indicating stronger interactions between the adsorbent surface and toluene.
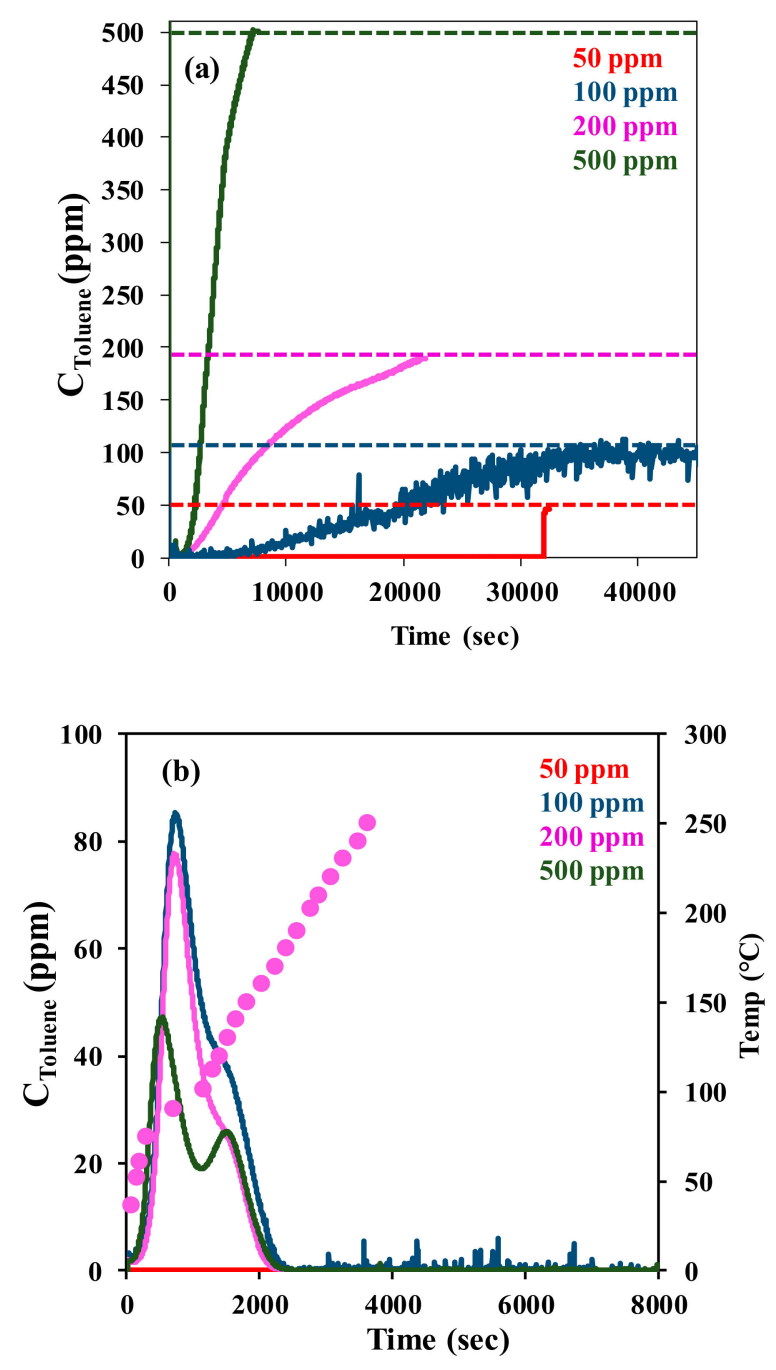

Figure 6. Cont. 


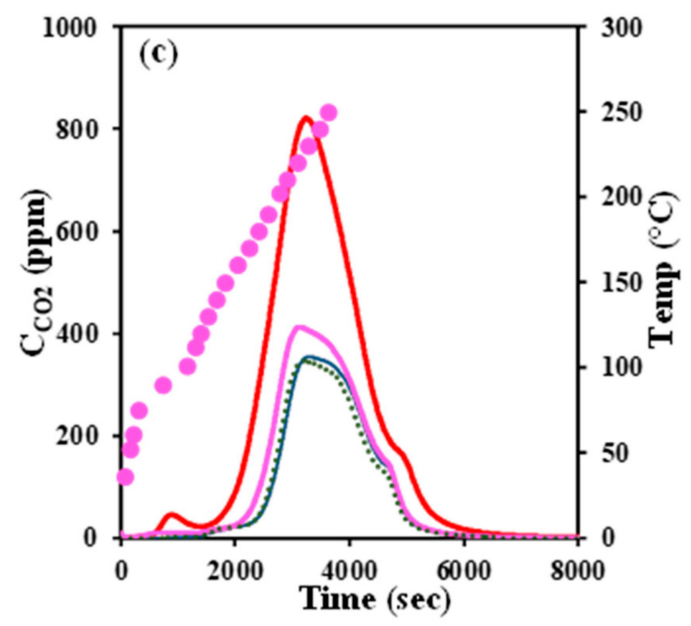

Figure 6. (a) Breakthrough curves of Hopcalite at different initial toluene concentration (dotted line corresponds to the concentration of toluene) (b) TPD profile of toluene (c) TPR profile of $\mathrm{CO}_{2}$ (circle represent the temperature).

Table 3. Adsorption (ADS) and desorption (DES) reaction of toluene on Hopcalite in He atmosphere.

\begin{tabular}{|c|c|c|c|c|c|}
\hline $\begin{array}{c}\text { Toluene Initial } \\
\text { Concentration (ppm) }\end{array}$ & $\begin{array}{l}\text { Tol. ADS at RT } \\
\left.(\mu \mathrm{mol} \mathrm{g})^{-1}\right)\end{array}$ & $\begin{array}{l}\text { Tol. DES at RT } \\
\left.(\mu \mathrm{mol} \mathrm{g})^{-1}\right)\end{array}$ & $\begin{array}{c}\text { Tol. DES } \\
\text { during TPR } \\
\left(\mu \mathrm{mol} \mathrm{g} \mathrm{g}^{-1}\right)\end{array}$ & $\begin{array}{c}\mathrm{CO}_{2} \text { Formed } \\
\text { during TPR } \\
\left(\mu \mathrm{mol} \mathrm{g}^{-1}\right)\end{array}$ & $\begin{array}{c}\mathrm{CO}_{2} \text { Yield } \\
(\%)\end{array}$ \\
\hline 50 & 472 & 0.0 & 0.6 & 3306 & 99.9 \\
\hline 100 & 384 & 38 & 160 & 1300 & 48.4 \\
\hline 200 & 392 & 74 & 115 & 1421 & 51.8 \\
\hline 500 & 379 & 73 & 107 & 1392 & 52.5 \\
\hline
\end{tabular}

Again, a singular behavior is observed using the lowest toluene concentration for which practically no toluene desorption is observed at room temperature. This indicates a strong interaction between toluene and Hopcalite when adsorption is conducted very slowly which is consistent with the long unsaturated time observed during the breakthrough experiment.

The gas phase analysis based on mass spectrometry reveals the formation of $\mathrm{CO}_{2}(\mathrm{~m} / \mathrm{z}=44)$ during the temperature programmed desorption process (Figure 6c). Interestingly, no other by products such as $\mathrm{CO}$ and $\mathrm{HCHO}$ have been observed which is indicative of a high selectivity of Hopcalite towards total oxidation. It can be seen that $\mathrm{CO}_{2}$ formation starts at $110-120^{\circ} \mathrm{C}$ when the lowest toluene concentration was used (50 ppm) and at approximately $150{ }^{\circ} \mathrm{C}$ for the higher toluene concentrations. It should be noted that, in this case, $\mathrm{CO}_{2}$ is produced by reducing the Hopcalite as no oxygen is provided by the gas flow. The highest amount of $\mathrm{CO}_{2}$ formation is observed (Table 3) in the case of an initial toluene concentration of $50 \mathrm{ppm}$ which is consistent with the absence of toluene desorption at room temperature or during TPR.

Therefore, it can be seen that the so-called irreversible adsorption of toluene (i.e., which does not desorb at RT or during heating) is favored when a low concentration of toluene is used in the inlet feed. This could be due to a better distribution of toluene species on the surface of Hopcalite, in particular within the mesoporous structure. Another possibility is that the irreversible adsorption is slow.

\subsubsection{Comparative Study of the Different Materials}

In the previous section, the dynamic toluene adsorption capacity of the adsorbent was determined by breakthrough curves. The breakthrough provides interesting information with regards to the adsorption properties of a solid but, as explained, cannot be reached in a real toluene abatement process because this would mean that a significant amount of toluene would still be released during the so-called breakthrough stage of the curve. In a real process, the adsorption would need to be stopped when a given threshold is reached corresponding to an acceptable level of toluene emission. 
For these reasons, a comparative study of the three different materials (Hopcalite, $\mathrm{UiO}-66-\mathrm{SO}_{3} \mathrm{H}$ and Ceria-NR) was performed using $100 \mathrm{ppm}$ toluene in the feed and the process was stopped when a concentration of approximately $10 \mathrm{ppm}$ was reached in the outlet flow. In this way, only the so-called "useful" adsorption capacity was taken into consideration.

To identify the catalytic properties, TPR has been performed in two different conditions: (1) in a pure inert gas, i.e., in a pure helium flow and (2) in an oxidizing atmosphere: $\mathrm{He}: \mathrm{O}_{2}=50: 50$ with a total flow $=100 \mathrm{~mL} \mathrm{~min}^{-1}$ in both cases. For each experiment, a fresh sample has been used.

All quantitative data obtained on the three materials in inert or oxidizing atmosphere are summarized in Table 4. The "useful" adsorption capacities follow this order: UiO-66- $\mathrm{SO}_{3} \mathrm{H}>\mathrm{Hopcalite}$ $>$ Ceria-NR which is consistent with the surface area of the respective solids (Table 1). Slight differences are observed on all samples between adsorption steps followed by TPR in He or in $\mathrm{He}: \mathrm{O}_{2}$ even though the adsorption process in always performed in similar conditions (without $\mathrm{O}_{2}$ ). This can be due to the difficulty in precisely evaluating the moment at which a 10-ppm residual toluene concentration is reached.

Table 4. Comparison of materials during toluene (100 ppm) adsorption followed by temperature programmed desorption in inert and oxidizing atmosphere.

\begin{tabular}{|c|c|c|c|c|c|}
\hline $\begin{array}{l}\text { Materials and TP } \\
\text { Atmosphere }\end{array}$ & $\begin{array}{l}\text { Tol. ADS at RT } \\
\left(\mu \mathrm{mol} \mathrm{g}^{-1}\right)\end{array}$ & $\begin{array}{l}\text { Tol. DES at RT } \\
\left.(\mu \mathrm{mol} \mathrm{g})^{-1}\right)\end{array}$ & $\begin{array}{c}\text { Tol. DES } \\
\text { during TPR } \\
\left(\mu \mathrm{mol} \mathrm{g}^{-1}\right)\end{array}$ & $\begin{array}{c}\mathrm{CO}_{2} \text { Formed } \\
\text { during TPR } \\
\left(\mu \mathrm{mol} \mathrm{g}^{-1}\right)\end{array}$ & $\begin{array}{c}\mathrm{CO}_{2} \text { Yield } \\
(\%)\end{array}$ \\
\hline Hopcalite-He & 136 & 1.4 & 23.8 & 780 & 81.9 \\
\hline Hopcalite-He: $\mathrm{O}_{2}$ & 108 & 1.8 & 6.8 & 698 & 92.3 \\
\hline Ceria-He & 73 & 8.6 & 60.5 & 28.0 & 5.5 \\
\hline Ceria-He:O 2 & 51 & 2.6 & 34.8 & 53.8 & 15.1 \\
\hline $\mathrm{UiO}-66-\mathrm{SO}_{3} \mathrm{H}-\mathrm{He}$ & 339 & 1.6 & 301 & 258 & 10.9 \\
\hline $\mathrm{UiO}-66-\mathrm{SO}_{3} \mathrm{H}-\mathrm{He}: \mathrm{O}_{2}$ & 315 & 2.3 & 267 & 315 & 14.3 \\
\hline
\end{tabular}

Figure 7 describes the toluene and $\mathrm{CO}_{2}$ concentration evolution during TPR which follows the adsorption sequence. First, it can be noted that on Hopcalite the overall process is much more efficient in terms of $\mathrm{CO}_{2}$ yield when the adsorption process is effectively limited to the useful adsorption capacity. Indeed, at a similar inlet concentration of $100 \mathrm{ppm}$, the $\mathrm{CO}_{2}$ yield reaches $81.9 \%$ when adsorption is limited to $10 \mathrm{ppm}$ max outlet concentration (Table 4 ) whereas only $48.4 \%$ was obtained when the total adsorption capacity is reached (Table 3). Clearly, the amount of reversibly adsorbed toluene is strongly reduced by limiting to the useful adsorption capacity. Still on Hopcalite, in the absence of $\mathrm{O}_{2}$, a desorption of toluene is observed from room temperature up to approximately $150{ }^{\circ} \mathrm{C}$. This desorption process appears in the form of two peaks, but this could be due to an irregularity in the rate of temperature increase around $80-100{ }^{\circ} \mathrm{C}$ as can be seen for all experiments.

The decrease in toluene desorption corresponds to the appearance of $\mathrm{CO}_{2}$ (Figure $7 \mathrm{a}^{\prime}$, dark blue curve) due to the reaction between toluene and the lattice oxygen species contained in the catalyst. In the presence of oxygen (red curves), the desorption of toluene is interrupted at lower temperature $\left(\mathrm{T}<100^{\circ} \mathrm{C}\right)$ by a sharp increase of $\mathrm{CO}_{2}$ production. The maximum $\mathrm{CO}_{2}$ production is reached at approximately $200^{\circ} \mathrm{C}$ and ends before the temperature reaches its maximum of $250{ }^{\circ} \mathrm{C}$ contrary to what is observed in the absence of a gaseous oxygen feed. These results are in good agreement with the excellent redox properties of Hopcalite for toluene oxidation as a very high conversion of toluene to $\mathrm{CO}_{2}$ is also obtained in the absence of oxygen ( $81.6 \mathrm{vs}$. $92.0 \%$ in absence or presence of $\mathrm{O}_{2}$, respectively). The catalytic properties of Hopcalite are evidenced by the lowering of reaction temperature and by a better total conversion to $\mathrm{CO}_{2}$. Interestingly, the maximum conversion of adsorbed toluene to $\mathrm{CO}_{2}$ is reached at a similar temperature in sequential mode with respect to the co-feed (Figure 5) for which $\mathrm{T}_{50}$ was observed at $185^{\circ} \mathrm{C}$.

A similar behavior is observed for $\mathrm{CeO}_{2}-\mathrm{NR}$ (Figure $7 \mathrm{~b}, \mathrm{~b}^{\prime}$ ) but with the major difference that the amounts of $\mathrm{CO}_{2}$ produced are considerably lower than for Hopcalite. It is nevertheless interesting 
to observe that more $\mathrm{CO}_{2}$ is produced in the low temperature range $\left(<20{ }^{\circ} \mathrm{C}\right)$ while practically no catalytic activity was observed at such low temperature in the co-feed (Figure 5). At higher temperature, the behavior of Ceria is less affected by the presence of $\mathrm{O}_{2}$ in the gas phase confirming that mostly subsurface oxygen may be involved.

With the objective to get a more accurate view on the redox properties of the two transition metal oxides, the quantity of extracted oxygen from the solids has been estimated from the amount of $\mathrm{CO}_{2}$ released during He-TPR after toluene adsorption (Table 4) to be compared with $\mathrm{H}_{2}$ consumption and thus released oxygen in the $\mathrm{H}_{2}$-TPR experiments (Table 1). For Hopcalite, the extracted oxygen to global oxygen $\left(\mathrm{O}_{\text {ext }} / \mathrm{O}_{\text {glo }}\right)$ atomic ratio estimated from the He-TPR (toluene) is approximately five times lower than the ratio obtained from the $\mathrm{H}_{2}$-TPR experiment (Table 5). This indicates that only the most reducible species or that a few layers of Hopcalite are involved in the reaction. Regarding $\mathrm{CeO}_{2}-\mathrm{NR}$, it is seen that the amount of extracted oxygen with respect to global oxygen $\left(\mathrm{O}_{\text {ext }} / \mathrm{O}_{\text {glo }}\right)$ in the TPR after toluene adsorption is approximately 10 times lower than the ratio extracted during $\mathrm{H}_{2}$-TPR. This is in good coherence with the $\mathrm{H}_{2}$-TPR profile (Figure 3) which indicated only a very small hydrogen consumption below $300{ }^{\circ} \mathrm{C}$ associated with adsorbed oxygen species. This result suggests that mostly surface and eventually some subsurface oxygen species participate in this oxidation process, which is in accordance with literature [42,45].

Table 5. Determination of extracted oxygen from solids in He atmosphere.

\begin{tabular}{|c|c|c|c|c|}
\hline Materials & $\begin{array}{c}\mathrm{H}_{2}-\mathrm{TPR} \\
\text { O Consumption } \\
\left(\mathrm{mmol} \mathrm{g}^{-1}\right)\end{array}$ & $\mathrm{O}_{\text {ext }} / \mathrm{O}_{\mathrm{glo}}{ }^{\mathrm{a}}$ & $\begin{array}{l}\text { He-TPR (Toluene) } \\
\text { O Consumption } \\
\left(\mathrm{mmol} \mathrm{g}^{-1}\right)\end{array}$ & $\mathrm{O}_{\text {ext }} / \mathrm{O}_{\text {glo }}{ }^{\mathrm{a}}$ \\
\hline Hopcalite & 11.1 & 0.47 & 2.00 & 0.08 \\
\hline $\mathrm{CeO}_{2}-\mathrm{NR}$ & 0.65 & 0.056 & 0.07 & 0.006 \\
\hline
\end{tabular}

In the case of UiO-66- $\mathrm{SO}_{3} \mathrm{H}$, most toluene desorbs from the surface of the catalysts without transformation (Figure 7c) and this is unaffected by the presence of $\mathrm{O}_{2}$ in the gas phase. Interestingly however, such desorption occurs at much higher temperature as the maximum toluene pressure is reached around $150{ }^{\circ} \mathrm{C}$ and ends around $200{ }^{\circ} \mathrm{C}$. Indeed, for other materials, such a process would end below $150^{\circ} \mathrm{C}$. This confirms the excellent adsorption capacities of $\mathrm{UiO}-66-\mathrm{SO}_{3} \mathrm{H}$. Significant amounts of $\mathrm{CO}_{2}$ are produced on this material but these are not affected by the presence of $\mathrm{O}_{2}$ (Figure $7 \mathrm{c}^{\prime}$ and Table 4). This indicates that toluene reacts with oxygen species contained in the solid. As UiO-66- $\mathrm{SO}_{3} \mathrm{H}$ is not expected to contain such redox properties, one can suppose that the $\mathrm{Zr}$ species at the surface of the MOF are partially oxidized and can provide such redox functionality but no actual catalytic properties. Also, UiO66- $\mathrm{SO}_{3} \mathrm{H}$ MOFs contain a lot of $\mathrm{B}-\mathrm{OH}$ groups, that could also be involved in the oxidation of toluene [46].
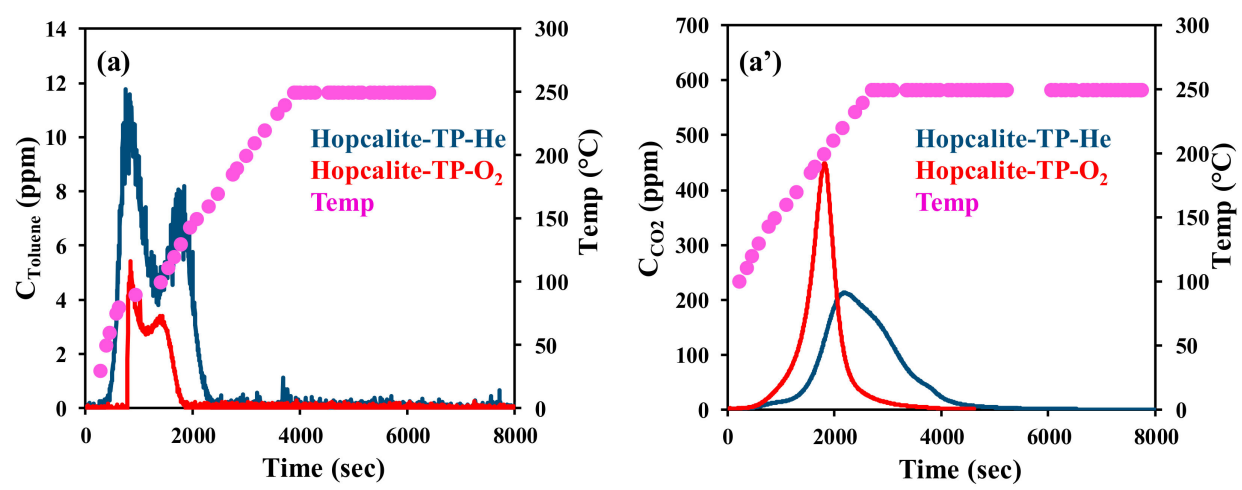

Figure 7. Cont. 

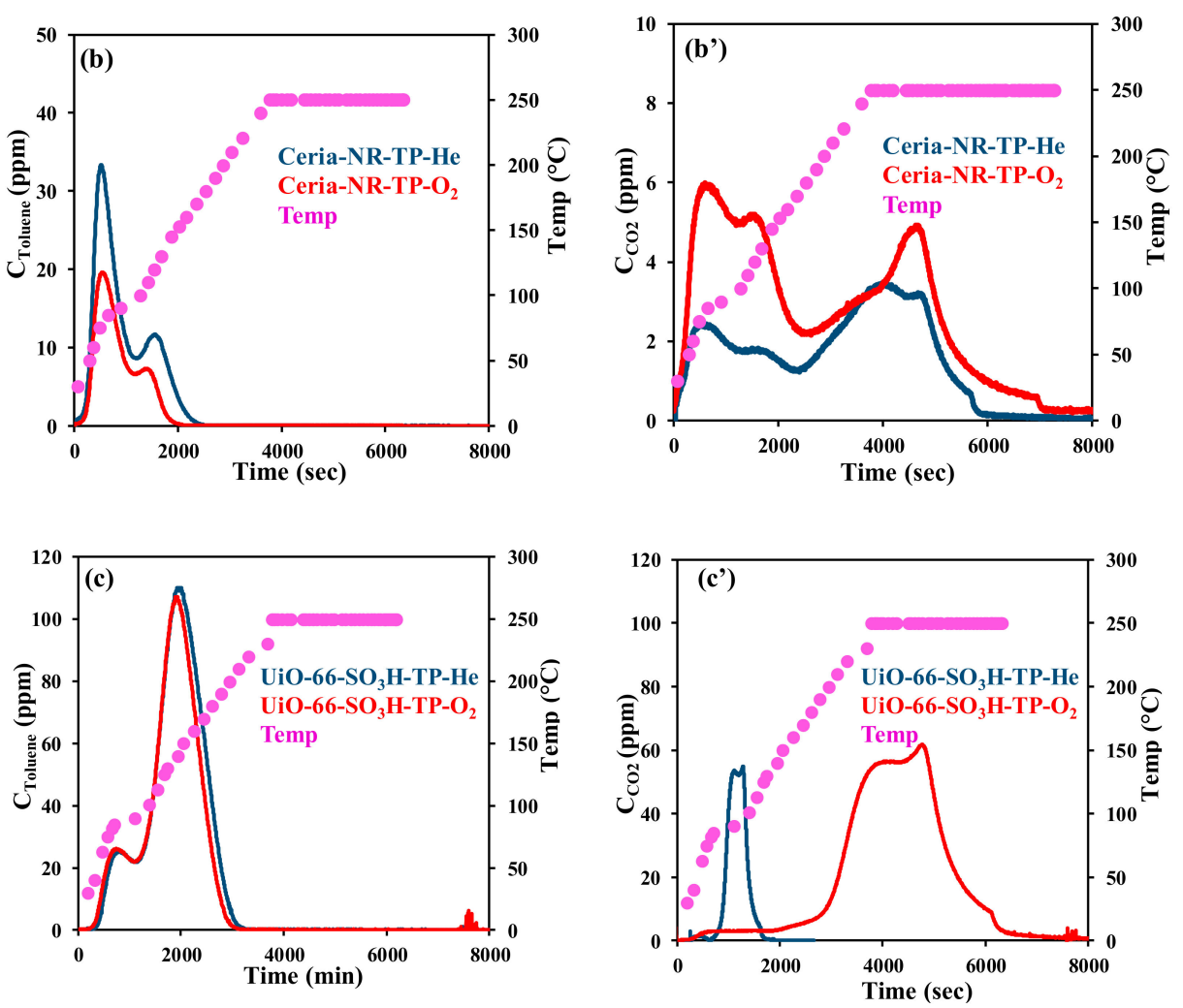

Figure 7. Toluene $(\mathbf{a}, \mathbf{b}, \mathbf{c})$ and $\mathrm{CO}_{2}\left(\mathbf{a}^{\prime}, \mathbf{b}^{\prime}, \mathbf{c}^{\prime}\right)$ concentration evolution during temperature programmed reaction on Hopcalite $\left(\mathbf{a}, \mathbf{a}^{\prime}\right), \mathrm{CeO}_{2}-\mathrm{NR}\left(\mathbf{b}, \mathbf{b}^{\prime}\right)$ and $\mathrm{UiO}-66-\mathrm{SO}_{3} \mathrm{H}\left(\mathbf{c}, \mathbf{c}^{\prime}\right)$.

To sum up the results, during sequential adsorption thermal oxidation Hopcalite possess high catalytic activity and high yield formation in absence and/ or presence of oxygen. Interestingly, in presence of oxygen the $\mathrm{CO}_{2}$ formation is take place at below $200{ }^{\circ} \mathrm{C}$. Moreover, no significant difference has been observed for Ceria-NR and UiO-66- $\mathrm{SO}_{3} \mathrm{H}$ in absence and presence of the oxygen. Although only a single adsorption-catalytic combustion sequence was performed in each case, this study shows that the Hopcalite stands as a good candidate due to its adsorption and redox properties. As the reaction takes place at temperatures significantly below that of the calcination, good reproducible cyclic behavior can be expected but will need to be explored in future. In the case of Ceria-NR and $\mathrm{UiO}-66-\mathrm{SO}_{3} \mathrm{H}$, future study should be focused on enhancing the catalytic activity by addition of an active phase.

\section{Materials and Methods}

\subsection{Catalyst Preparation}

Hopcalite (Purelyst MD101; bulk pellets) was purchased from PureSphere Co., Ltd. The approximate chemical composition of Hopcalite was: $\mathrm{CuO}>23 \mathrm{~mol} \%, \mathrm{MnO}_{2}>69 \mathrm{~mol} \%$ with the presence of $\mathrm{K}$ and Al. The pellets (diameter of $3 \pm 0.5 \mathrm{~mm}$ ) with a length of $10 \mathrm{~mm}$ were crushed and sieved to select the 200-300 $\mu \mathrm{m}$ particle size range. The resulting black powder was calcined at $300{ }^{\circ} \mathrm{C}$ for $4 \mathrm{~h}$ in flowing dry air $\left(2^{\circ} \mathrm{C} \mathrm{min}^{-1}\right)$.

$\mathrm{CeO}_{2}-\mathrm{NR}$ was synthesized according to the procedure reported by $\mathrm{Du}$ et al. [29]. Typically, $1.74 \mathrm{~g}$ of $\mathrm{Ce}\left(\mathrm{NO}_{3}\right)_{3} \cdot 6 \mathrm{H}_{2} \mathrm{O}$ (Sigma Aldrich, 99\%) and an appropriate amount of $\mathrm{NaOH}$ (19.2 g pellets, Sigma Aldrich, $>99 \%$ ) were dissolved separately in $40 \mathrm{~mL}$ of distilled water. The solutions were mixed together and kept stirring for $30 \mathrm{~min}$. The slightly purple color slurry was then transferred into a $100 \mathrm{~mL}$ Teflon-lined stainless-steel autoclave, heated at $100{ }^{\circ} \mathrm{C}$ for $24 \mathrm{~h}$ in a laboratory oven and cooled to $25^{\circ} \mathrm{C}$. The resulting precipitate was collected by centrifugation at $600 \mathrm{rpm}$ for $10 \mathrm{~min}$, 
washed several times with distilled water and ethanol $(30 \mathrm{~mL})$, before being dried at $80^{\circ} \mathrm{C}$ for $12 \mathrm{~h}$. The resulting pale-yellow powder was calcined at $400{ }^{\circ} \mathrm{C}$ for $5 \mathrm{~h}$ in flowing dry air $\left(2{ }^{\circ} \mathrm{C} \mathrm{min}-1\right)$.

UiO-66- $\mathrm{SO}_{3} \mathrm{H}$ (UiO: University of Oslo) was synthesized according to a method described in literature [18]. A mixture, containing $\mathrm{ZrO}_{2} \mathrm{Cl}_{2} \cdot 8 \mathrm{H}_{2} \mathrm{O}(0.31 \mathrm{mmol}$, acbcr chemical, 98\%), terephalic acid $(0.31 \mathrm{mmol}$, Sigma Aldrich, $98 \%)$, 2-sulphoterephthalic acid mono sodium salt $\left(\mathrm{H}_{2} \mathrm{DBC}-\mathrm{SO}_{3} \mathrm{Na}\right.$, $0.31 \mathrm{mmol}$, TCI chemicals, $>98 \%$ ), and formic acid (1.2 mL, $3.18 \mathrm{mmol}$, Sigma Aldrich, $>89-91 \%$ ), was dissolved in N,N Dimethyl acetamide (DMA, $3 \mathrm{~mL}, 32.5 \mathrm{mmol}$, Sigma chemicals, $>99 \%$ ) and the solution was placed in a Pyrex tube $(10 \mathrm{~mL})$. The filled sealed Pyrex tube was submitted to solvothermal conditions $\left(150^{\circ} \mathrm{C}\right.$ for $24 \mathrm{~h}$ ) and cooled down naturally to $25^{\circ} \mathrm{C}$. The white precipitate was collected by filtration, washed with acetone and dried in ambient condition overnight. A mild three-step activation procedure was employed in order to remove the guest $\mathrm{SO}_{3} \mathrm{H}$ linker molecules encapsulated within the pores of the as-synthesized MOF. At first, the guest molecules were exchanged by stirring the as-synthesized UiO-66- $\mathrm{SO}_{3} \mathrm{H}(0.3 \mathrm{~g})$ in dimethylformamide (DMF, $20 \mathrm{~mL}$, Fluka chemicals, $>99.5 \%$ ) at ambient conditions for $12 \mathrm{~h}$. In the second step, the DMF-exchanged compound was stirred in methanol ( $30 \mathrm{~mL}$, Fluka chemicals, $>99.5 \%$ ) for $24 \mathrm{~h}$. In the third step, methanol release was carried out using low temperature heating $\left(65^{\circ} \mathrm{C}\right)$ under dynamic vacuum for $24 \mathrm{~h}$ to acquire thermally activated $\mathrm{UiO}-66-\mathrm{SO}_{3} \mathrm{H}$.

\subsection{Characterization of the Materials}

XRD patterns were recorded using a D8 Advanced Bruker AXS diffractometer with Ni-filtered $\mathrm{Cu}-\mathrm{K} \alpha$ radiation. $\mathrm{XRD}$ analysis was performed in the $5-80^{\circ} 2 \theta$ range (step size $0.01^{\circ}$, time per step- 1 s). The mean crystallite size for $\mathrm{CeO}_{2}$ was estimated by the Debye-Scherrer formula according to the following equation:

$$
\mathrm{D}=\frac{\mathrm{K} \lambda}{\beta^{\prime} \cos \theta}
$$

where $\lambda(1.5406 \AA)$ is the $\mathrm{X}$-ray wavelength, $\mathrm{K}$ a particle shape factor, taken as $0.9, \beta^{\prime}$ is defined as the width at half maximum of the peak corrected from apparatus broadening (in radians) and $\theta$ the position (angle in radians) of the peak.

The textural properties were determined from the adsorption/desorption isotherms of $\mathrm{N}_{2}$ at- $196^{\circ} \mathrm{C}$ using a Micrometrics TriStar II 3020 instrument. Prior to adsorption measurement, Hopcalite, Ceria-NR and UiO-66-SO ${ }_{3} \mathrm{H}$ were degassed at $150{ }^{\circ} \mathrm{C}$ for $5 \mathrm{~h}, 250{ }^{\circ} \mathrm{C}$ for $5 \mathrm{~h} \mathrm{[47]} \mathrm{and} 100{ }^{\circ} \mathrm{C}$ for $24 \mathrm{~h}$ under vacuum $(\mathrm{P}=0.05 \mathrm{mbar})$, respectively. The pore size distributions were determined from desorption branches of the isotherms using the Barrett-Joyner-Halanda $(\mathrm{BJH})$ method. Total pore volume $\left(\mathrm{V}_{\mathrm{p}}\right)$ was estimated from the amount of nitrogen adsorbed at a relative pressure $\left(\mathrm{P} / \mathrm{P}^{0}\right)$ of 0.99 .

$\mathrm{H}_{2}$-temperature programmed reduction $\left(\mathrm{H}_{2}\right.$-TPR) experiments were performed using a Micrometrics model autochem II 2920 equipped with a quartz U-shaped micro reactor. $50 \mathrm{mg}$ of the samples was exposed to a $5 \% \mathrm{H}_{2} / \mathrm{Ar}$ gas mixture $\left(50 \mathrm{~mL} \mathrm{~min}{ }^{-1}\right.$ ) from $25^{\circ} \mathrm{C}$ to $1000{ }^{\circ} \mathrm{C}$ at a heating rate of $10^{\circ} \mathrm{C} \mathrm{min}^{-1}$.

X-ray photoelectron spectroscopy (XPS) experiments were performed using an AXIS Ultra DLD Kratos spectrometer equipped with a monochromatic aluminum source $(\mathrm{Al} \mathrm{K} \alpha=1486.7 \mathrm{eV})$ and charge compensation gun. The binding energies (BE) were referenced from adventitious C $1 \mathrm{~s}$ at $284.8 \mathrm{eV}$.

TGA (thermo gravimetric analysis)/DSC (differential scanning calorimetry) measurements were performed using a TA instrument SDT 2960 DSC-TGA V3.0F. Approximately $10 \mathrm{mg}$ of samples were heated from $25{ }^{\circ} \mathrm{C}$ to $800{ }^{\circ} \mathrm{C}\left(10{ }^{\circ} \mathrm{C} \mathrm{min}{ }^{-1}\right)$ in flowing dry air $\left(50 \mathrm{~mL} \mathrm{~min}{ }^{-1}\right)$. For UiO-66- $\mathrm{SO}_{3} \mathrm{H}$, approximately $2 \mathrm{mg}$ was used due to strong exothermicity of the decomposition process.

\subsection{Catalytic Activity Tests}

The scheme of the home-made experimental set-up for toluene abatement experiments is displayed in Figure 8. All experiments were carried out using a Pyrex glass reactor (inner diameter 
$10 \mathrm{~mm}$, wall thickness $1 \mathrm{~mm}$ ) placed into a coaxial tubular furnace which was temperature regulated (TEMPATRON, PID500). All gas flows were regulated using mass flow controllers (Bronkhorst).

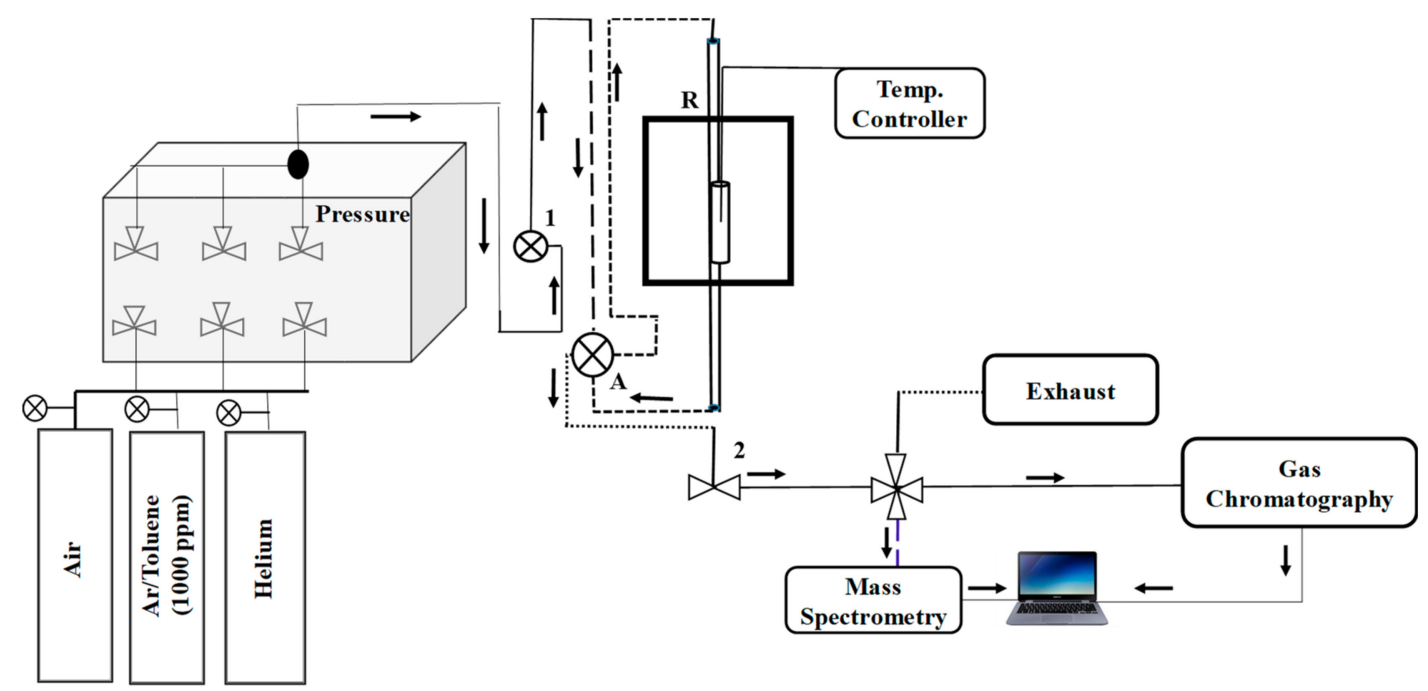

Figure 8. Schematic diagram of the experimental set-up used for abatement of toluene by adsorption/catalytic oxidation.

\subsubsection{Catalytic Oxidation}

Typically, $0.2 \mathrm{~g}$ of the sample was placed in the fixed bed reactor. Before each test, the solids were treated in flowing dry air $\left(100 \mathrm{~mL} \mathrm{~min}{ }^{-1}\right)$ at $330{ }^{\circ} \mathrm{C}$ for $30 \mathrm{~min}\left(2{ }^{\circ} \mathrm{C} \mathrm{min}^{-1}\right)$. The catalysts were then exposed to the reactive atmosphere (1000 ppmv of toluene diluted in synthetic air) at a flow rate of $100 \mathrm{~mL} \mathrm{~min}{ }^{-1}$. The temperature was allowed to decrease from $330^{\circ} \mathrm{C}$ to $30^{\circ} \mathrm{C}$ (with a decreasing rate of $0.5^{\circ} \mathrm{C} \cdot \mathrm{min}^{-1}$ to $150{ }^{\circ} \mathrm{C}$ followed by $0.2{ }^{\circ} \mathrm{C} \cdot \mathrm{min}^{-1}$ from $150{ }^{\circ} \mathrm{C}$ to $30^{\circ} \mathrm{C}$ ). The off-gases were analyzed on-line using a gas chromatograph ( $\mu \mathrm{GC}$, R3000 Agilent Gas Chromatograph) equipped with a thermal conductivity detector (TCD) using a Stabilwax $(10 \mathrm{~m})$ column. The results were expressed in terms of toluene conversion into carbon dioxide:

$$
X(\%)=\frac{\left[\mathrm{CO}_{2}\right]_{\text {out }}}{7 \times\left[\mathrm{C}_{7} \mathrm{H}_{8}\right]_{\text {in }}} \times 100
$$

where $X$ is the toluene conversion into $\mathrm{CO}_{2}$ while $\left[\mathrm{CO}_{2}\right]_{\text {in }}$ and $\left[\mathrm{C}_{7} \mathrm{H}_{8}\right]_{\text {out }}$ are the $\mathrm{CO}_{2}$ an $\mathrm{C}_{7} \mathrm{H}_{8}$ concentrations at the inlet and outlet of the reactor, respectively.

\subsubsection{Sequential Adsorption/Thermal Oxidation}

For the sequential adsorption/regeneration experiment, He was used as a carrier gas while toluene was provided from a premixed gas cylinder ( $0.1 \mathrm{vol} \%$ toluene in argon). The evolution of the gas phase composition was monitored using an online mass spectrometer (Omnistar, Pfeiffer Vacuum, Model GSD 30102$)$. Approximately $0.3 \mathrm{~g}$ of the sample was heated in flowing dry air $\left(100 \mathrm{~mL} \mathrm{~min}^{-1}\right)$ at $150{ }^{\circ} \mathrm{C}$ for $4 \mathrm{~h}\left(5^{\circ} \mathrm{C} \cdot \mathrm{min}^{-1}\right)$ to clean the surface from absorbed species. The sample was then cooled down to room temperature. Meanwhile, the required flow of He and toluene in the argon flow was set to achieve the desired initial toluene concentration (e.g., for $100 \mathrm{ppm}$ toluene: $\mathrm{He}=90 \mathrm{~mL} \mathrm{~min}{ }^{-1}$; toluene/argon $=10 \mathrm{~mL} \mathrm{~min}^{-1}$ ). The toluene containing flow was passed through a by-pass and then switched to the reactor to perform the adsorption of toluene. The amount of adsorbed toluene was calculated comparing the initial and residual toluene concentrations. The toluene/argon flow was then switched off and the helium flow adjusted to $100 \mathrm{~mL} \mathrm{~min}^{-1}$ in order to assess the amount of toluene reversibly adsorbed on the sample. Finally, the sample was heated up to $250{ }^{\circ} \mathrm{C}$ (heating rate $2{ }^{\circ} \mathrm{C} \mathrm{min}^{-1}$, hold at $250{ }^{\circ} \mathrm{C}$ for $1.5 \mathrm{~h}$ ) in pure $\mathrm{He}$ or in $\mathrm{O}_{2}: \mathrm{He}$ (50:50). 
The amount of toluene desorbed at room temperature $\left(\mathrm{q}(\mathrm{Tol})_{\text {desRT }}\right)$, desorbed during the temperature programmed reaction $\left(\mathrm{q}(\mathrm{Tol})_{\text {desTPR }}\right)$, the corresponding amount of $\mathrm{CO}_{2}$ formation $\left(\mathrm{q}\left(\mathrm{CO}_{2}\right)_{\mathrm{TPR}}\right)$, and the amount of toluene adsorbed $\left(\mathrm{q}(\mathrm{Tol})_{\mathrm{ads}}\right)$ were calculated as follows:

$$
\begin{gathered}
\mathrm{q}(\mathrm{Tol})_{\text {desRT }}\left(\mu \mathrm{mol} . \mathrm{g}^{-1}\right)=A \times \sum_{0}^{t}\left(\frac{P(\mathrm{Tol})_{t}+P(\mathrm{Tol})_{t+1}}{2}\right) \times \Delta t \\
\mathrm{q}(\mathrm{Tol})_{\text {desTPR }}\left(\mu \mathrm{mol} . \mathrm{g}^{-1}\right)=A \times \sum_{0}^{t}\left(\frac{P(\mathrm{Tol})_{t}+P(\mathrm{Tol})_{t+1}}{2}\right) \times \Delta t \\
\mathrm{q}\left(\mathrm{CO}_{2}\right)_{\mathrm{TPR}}\left(\mu \mathrm{mol} . \mathrm{g}^{-1}\right)=A \times \sum_{0}^{t}\left(\frac{P\left(\mathrm{CO}_{2}\right)_{t}+P\left(\mathrm{CO}_{2}\right)_{t+1}}{2}\right) \times \Delta t \\
\mathrm{q}(\mathrm{Tol})_{\text {ads }}\left(\mu \mathrm{mol} . \mathrm{g}^{-1}\right)=\mathrm{q}(\mathrm{Tol})_{\operatorname{desRT}}+\mathrm{q}(\mathrm{Tol})_{\text {desTPR }}+\frac{\mathrm{q}\left(\mathrm{CO}_{2}\right)_{\mathrm{TPR}}}{7}
\end{gathered}
$$

where $\mathrm{P}(\mathrm{Tol})_{\mathrm{t}}$ and $\mathrm{P}\left(\mathrm{CO}_{2}\right)_{\mathrm{t}}$ are the partial pressures of toluene and $\mathrm{CO}_{2}$ at a given time expressed in atm, $\mathrm{t}$ is in $\mathrm{min}, A=\frac{10^{+3}}{R \times T} \times \frac{F}{M}$ in which $\mathrm{F}$ is the total gas flow in $\mathrm{mL} \mathrm{min}^{-1}, \mathrm{~m}$ is the mass of the material in $\mathrm{g}, \mathrm{T}=293 \mathrm{~K}$, and $\mathrm{R}=8.0206 \mathrm{~L} \mathrm{~atm} \mathrm{~mol}^{-1} \mathrm{~K}^{-1}$.

The $\mathrm{CO}_{2}$ yield was estimated from the formula given below:

$$
\mathrm{CO}_{2} \text { Yield }(\%)=\frac{\mathrm{q}\left(\mathrm{CO}_{2}\right)_{\mathrm{TPR}}}{7 \times \mathrm{q}(\mathrm{Tol})_{\mathrm{ads}}} \times 100
$$

The $\left(\mathrm{O}_{\text {ext }} / \mathrm{O}_{\text {glo }}\right)$ atomic ratio where $\mathrm{O}_{\text {ext }}$ is the amount of oxygen extracted from the solid and $\mathrm{O}_{\text {glo }}$ the global oxygen content of the solid was also determined in this study. $\mathrm{O}_{\text {ext }}$ was estimated from the release amount of $\mathrm{CO}_{2}$ during the He-TPR experiments owing to the $\mathrm{O}$ balance as follow:

$$
\begin{gathered}
\mathrm{C}_{7} \mathrm{H}_{8}+18 \mathrm{O}=7 \mathrm{CO}_{2}+4 \mathrm{H}_{2} \mathrm{O} \\
n\left(\mathrm{O}_{E x t}\right)=2 \times \mathrm{n}\left(\mathrm{CO}_{2}\right)_{\mathrm{TPR}}+\mathrm{n}\left(\mathrm{H}_{2} \mathrm{O}\right)_{\mathrm{TPR}}=\frac{18}{7} \mathrm{n}\left(\mathrm{CO}_{2}\right)_{\mathrm{TPR}}
\end{gathered}
$$

\section{Conclusions}

The adsorption capacity and catalytic activity of three different materials have been compared for toluene oxidation in co-feed mode and in a novel sequential mode. Among all studied samples, Hopcalite shows the best toluene oxidation and sequential adsorption-thermal oxidation properties. On this material, it has been shown that the adsorption process can be efficient and that the optimal adsorption capacity can be reached at low $(<100 \mathrm{ppm})$ toluene feed. At higher toluene feed concentration, reversible adsorption takes place which is detrimental for the efficiency of the abatement process. The notion of "useful" adsorption capacity is therefore employed to describe the amount of toluene adsorbed before the residual toluene pressure reaches a given acceptable threshold. For instance, with a 10-ppm threshold, the adsorption is mostly irreversible and good toluene abatement performance is reached. Indeed, at a similar inlet concentration of toluene (100 ppm), the $\mathrm{CO}_{2}$ yield is almost twice as large when adsorption is limited to adsorption capacity as compared to that of the obtained adsorption reaching full capacity. In the toluene oxidation step of the process, Hopcalite exhibits the best catalytic oxidation properties allowing to reach high levels of toluene conversion into $\mathrm{CO}_{2}$ and low pollutant release by desorption.

Although the Ceria-NR possesses some catalytic properties, its reactivity at low temperature is not sufficient to convert adsorbed toluene in a useful temperature range, i.e., below $150{ }^{\circ} \mathrm{C}$. Overall performances are thus insufficient to be considered for such a sequential process unless the catalytic performance is enhanced by the addition of an active catalytic phase. $\mathrm{UiO}-66-\mathrm{SO}_{3} \mathrm{H}$ on 
the other hand is a promising material with respect to its excellent adsorption capacities. However, its catalytic properties also need to be improved in order to be considered for a sequential process.

Generally, this exploratory study allows to identify key criteria for the selection of candidate materials for a sequential adsorption-catalysis process for toluene abatement. This study opens the path for further investigations in the search for innovative materials associating active catalytic properties and high-performance adsorption capacities. These may be constituted by well-known adsorbent materials associated with supported catalytically active phases. Alternatively, bulk materials possessing both adsorption and catalytic requirements can be considered and Hopcalite appears as a good candidate in this purpose. Deeper studies of sequential processes are nevertheless required, in particular with regard to the stability of this material in repetitive working conditions. The influence of water vapor and of other competitive pollutants will also need to be carefully investigated in order to simulate realistic pollution abatement conditions.

Author Contributions: Conceptualization, J.-M.G. and A.L.; Funding acquisition, J.-F.L. and R.M.; Investigation, S.S., J.-M.G., S.K.P.V., R.B., and A.L.; Supervision, J.-M.G., N.D.G., and A.L.; Visualization, S.S.; Writing-original draft, S.S.; Writing-review \& editing, J.-M.G., S.K.P.V., R.B., K.L., P.V.D.V., J.-F.L., R.M., N.D.G., and A.L. All authors have read and agreed to the published version of the manuscript.

Funding: The authors acknowledge the support of the European Union for funding this work through an INTERREG V France-Wallonie-Vlaanderen project "Depollutair". The Fonds Européen de Développement Régional (FEDER), CNRS, Région Hauts-de-France, Ministère de l'Education Nationale de l'Enseignement Supérieur et de la Recherche and Chevreul Institut are acknowledged for funding of XPS spectrometers and XRD instruments. This research was carried out in the French-Belgium Associated International Laboratory "Plasma \& Catalysis" supported by the Universities of Lille and Ghent.

Conflicts of Interest: The authors declare no conflicts of interest.

\section{References}

1. Dinh, T.V.; Choi, I.Y.; Son, Y.S.; Song, K.Y.; Sunwoo, Y.; Kim, J.C. Volatile organic compounds (VOCs) in surface coating materials: Their compositions and potential as an alternative fuel. J. Environ. Manag. 2016, 168, 157-164. [CrossRef] [PubMed]

2. Liu, G.; Ji, J.; Huang, H.; Xie, R.; Feng, Q.; Shu, Y.; Zhan, Y.; Fang, R.; He, M.; Liu, S.; et al. UV/H2O2: An efficient aqueous advanced oxidation process for VOCs removal. Chem. Eng. J. 2017, 324, 44-50. [CrossRef]

3. He, C.; Cheng, J.; Zhang, X.; Douthwaite, M.; Pattisson, S.; Hao, Z. Recent Advances in the Catalytic Oxidation of Volatile Organic Compounds: A Review Based on Pollutant Sorts and Sources. Chem. Rev. 2019, 119, 4471-4568. [CrossRef] [PubMed]

4. Wang, Y.; Su, X.; Xu, Z.; Wen, K.; Zhang, P.; Zhu, J.; He, H. Preparation of surface-functionalized porous clay heterostructures via carbonization of soft-template and their adsorption performance for toluene. Appl. Surf. Sci. 2016, 363, 113-121. [CrossRef]

5. Romero, D.; Chlala, D.; Labaki, M.; Royer, S.; Bellat, J.P.; Bezverkhyy, I.; Giraudon, J.M.; Lamonier, J.F. Removal of toluene over naX zeolite exchanged with $\mathrm{Cu}^{2+}$. Catalysts 2015, 5, 1479-1497. [CrossRef]

6. Darracq, G.; Couvert, A.; Couriol, C.; Amrane, A.; Le Cloirec, P. Removal of hydrophobic volatile organic compounds in an integrated process coupling absorption and biodegradation-selection of an organic liquid phase. Water. Air. Soil Pollut. 2012, 223, 4969-4997. [CrossRef]

7. Liu, B.; Li, X.; Zhao, Q.; Liu, J.; Liu, S.; Wang, S.; Tadé, M. Insight into the mechanism of photocatalytic degradation of gaseous o-dichlorobenzene over flower-type V2O5 hollow spheres. J. Mater. Chem. A 2015, 3, 15163-15170. [CrossRef]

8. Yang, C.; Miao, G.; Pi, Y.; Xia, Q.; Wu, J.; Li, Z.; Xiao, J. Abatement of various types of VOCs by adsorption/catalytic oxidation: A review. Chem. Eng. J. 2019, 370, 1128-1153. [CrossRef]

9. Chen, B.; Wu, L.; Wu, B.; Wang, Z.; Yu, L.; Crocker, M.; Zhu, A.; Shi, C. Catalytic Materials for Low Concentration VOCs Removal through "Storage-Regeneration" Cycling. ChemCatChem 2019, 11, 3646-3661. [CrossRef]

10. Sultana, S.; Vandenbroucke, A.M.; Leys, C.; De Geyter, N.; Morent, R. Abatement of VOCs with alternate adsorption and plasma-assisted regeneration: A review. Catalysts 2015, 5, 718-746. [CrossRef] 
11. Xu, W.; Xu, X.; Wu, J.; Fu, M.; Chen, L.; Wang, N.; Xiao, H.; Chen, X.; Ye, D. Removal of toluene in adsorption-discharge plasma systems over a nickel modified SBA-15 catalyst. RSC Adv. 2016, 6, 104104-104111. [CrossRef]

12. Reungoat, J.; Pic, J.S.; Manro, M.H.; Debellefontaine, H. Adsorption of nitrobenzene from water onto high silica zeolites and regeneration by ozone. Sep. Sci. Technol. 2007, 42, 1447-1463. [CrossRef]

13. Guillemot, M.; Mijoin, J.; Mignard, S.; Magnoux, P. Volatile organic compounds (VOCs) removal over dual functional adsorbent/catalyst system. Appl. Catal. B Environ. 2007, 75, 249-255. [CrossRef]

14. Dey, S.; Chandra, G.D. A Review of Synthesis, Structure and Applications in Hopcalite Catalysts for Carbon Monoxide Oxidation; Springer: Singapore, 2019; Volume 3, ISBN 0123456789.

15. Pei, J.; Han, X.; Lu, Y. Performance and kinetics of catalytic oxidation of formaldehyde over copper manganese oxide catalyst. Build. Environ. 2015, 84, 134-141. [CrossRef]

16. Wei, G.; Zhang, Q.; Zhang, D.; Wang, J.; Tang, T.; Wang, H.; Liu, X.; Song, Z.; Ning, P. The influence of annealing temperature on copper-manganese catalyst towards the catalytic combustion of toluene: The mechanism study. Appl. Surf. Sci. 2019, 497, 143777. [CrossRef]

17. Hu, Z.; Liu, X.; Meng, D.; Guo, Y.; Guo, Y.; Lu, G. Effect of Ceria Crystal Plane on the Physicochemical and Catalytic Properties of Pd / Ceria for CO and Propane Oxidation. ACS Catal. 2016, 6, 2265-2279. [CrossRef]

18. Biswas, S.; Van Der Voort, P. A General Strategy for the Synthesis of Functionalised UiO-66 Frameworks: Characterisation, Stability and $\mathrm{CO}_{2}$ Adsorption Properties. Eur. J. Inorg. Chem 2013, 2154-2160. [CrossRef]

19. Zhang, X.; Yang, Y.; Lv, X.; Wang, Y.; Liu, N.; Chen, D.; Cui, L. Adsorption/desorption kinetics and breakthrough of gaseous toluene for modified microporous-mesoporous UiO-66 metal organic framework. J. Hazard. Mater. 2019, 366, 140-150. [CrossRef]

20. Nguyen, H.G.T.; Mao, L.; Peters, A.W.; Audu, C.O.; Brown, Z.J.; Farha, O.K.; Hupp, J.T.; Nguyen, S.T. Comparative study of titanium-functionalized UiO-66: Support effect on the oxidation of cyclohexene using hydrogen peroxide. Catal. Sci. Technol. 2015, 5, 4444-4451. [CrossRef]

21. Wei, C.; Hou, H.; Wang, E.; Lu, M. Preparation of a Series of PdatUIO-66 by a double-solvent method and its catalytic performance for toluene oxidation. Materials 2020, 13, 88. [CrossRef]

22. Zhang, X.; Song, L.; Bi, F.; Zhang, D.; Wang, Y.; Cui, L. Catalytic oxidation of toluene using a facile synthesized Ag nanoparticle supported on UiO-66 derivative. J. Colloid Interface Sci. 2020, 571, 38-47. [CrossRef] [PubMed]

23. Njagi, E.C.; Chen, C.H.; Genuino, H.; Galindo, H.; Huang, H.; Suib, S.L. Total oxidation of CO at ambient temperature using copper manganese oxide catalysts prepared by a redox method. Appl. Catal. B Environ. 2010, 99, 103-110. [CrossRef]

24. Désaunay, T.; Bonura, G.; Chiodo, V.; Freni, S.; Couzinié, J.P.; Bourgon, J.; Ringuedé, A.; Labat, F.; Adamo, C.; Cassir, M. Surface-dependent oxidation of $\mathrm{H}_{2}$ on $\mathrm{CeO}_{2}$ surfaces. J. Catal. 2013, 297, 193-201. [CrossRef]

25. Cavka, J.H.; Jakobsen, S.; Olsbye, U.; Guillou, N.; Lamberti, C.; Bordiga, S.; Lillerud, K.P. A New Zirconium Inorganic Building Brick Forming Metal Organic Frameworks with Exceptional Stability. J. Am. Chem. Soc. 2008, 130, 13850-13851. [CrossRef]

26. Silva, C.G.; Luz, I.; Llabrés I Xamena, F.X.; Corma, A.; García, H. Water stable Zr-Benzenedicarboxylate metal-organic frameworks as photocatalysts for hydrogen generation. Chem. A Eur. J. 2010, 16, 11133-11138. [CrossRef]

27. Øien, S.; Wragg, D.; Reinsch, H.; Svelle, S.; Bordiga, S.; Lamberti, C.; Lillerud, K.P. Detailed Structure Analysis of Atomic Positions and Defects in Zirconium Metal-Organic Frameworks. Cryst. Growth Des. 2014, 14, 5370-5372. [CrossRef]

28. Yuan, Z.; Idakiev, V.; Tabakova, T.; Ren, T.; Su, B. Mesoporous and nanostructured $\mathrm{CeO}_{2}$ as supports of nano-sized gold catalysts for low-temperature water-gas shift reaction. Catal. Today 2008, 131, $203-210$. [CrossRef]

29. Du, X.; Zhang, D.; Shi, L.; Gao, R.; Zhang, J. Morphology Dependence of Catalytic Properties of $\mathrm{Ni} / \mathrm{CeO}_{2}$ Nanostructures for Carbon Dioxide Reforming of Methane. J.Phys.Chem.C. 2012, 116, 10009-10016. [CrossRef]

30. Xiao, Z.; Ji, S.; Li, Y.; Hou, F.; Zhang, H.; Zhang, X. Tuning oxygen vacancies on mesoporous ceria nanorods by metal doping: Controllable magnetic property. Appl. Surf. Sci. 2018, 455, 1037-1044. [CrossRef]

31. Liang, W.; Coghlan, C.J.; Ragon, F.; Rubio-Martinez, M.; D'Alessandro, D.M.; Babarao, R. Defect engineering of UiO-66 for $\mathrm{CO}_{2}$ and $\mathrm{H}_{2} \mathrm{O}$ uptake-A combined experimental and simulation study. Dalt. Trans. 2016, 4496-4500. [CrossRef] 
32. Yang, F.; Huang, H.; Wang, X.; Li, F.; Gong, Y.; Zhong, C.; Li, J.R. Proton Conductivities in Functionalized UiO-66: Tuned Properties, Thermogravimetry Mass, and Molecular Simulation Analyses. Cryst. Growth Des. 2015, 15, 5827-5833. [CrossRef]

33. Donnadio, A.; Narducci, R.; Casciola, M.; Marmottini, F.; D'Amato, R.; Jazestani, M.; Chiniforoshan, H.; Costantino, F. Mixed Membrane Matrices Based on Nafion/UiO-66/SO3H-UiO-66 Nano-MOFs: Revealing the Effect of Crystal Size, Sulfonation, and Filler Loading on the Mechanical and Conductivity Properties. ACS Appl. Mater. Interfaces 2017, 9, 42239-42246. [CrossRef] [PubMed]

34. Lin, Z.; Cai, X.; Fu, Y.; Zhu, W.; Zhang, F. Cascade catalytic hydrogenation-cyclization of methyl levulinate to form $\gamma$-valerolactone over Ru nanoparticles supported on a sulfonic acid-functionalized UiO-66 catalyst. RSC Adv. 2017, 7, 44082-44088. [CrossRef]

35. Kim, J.; Min, Y.H.; Lee, N.; Cho, E.; Kim, K.Y.; Jeong, G.; Moon, S.K.; Joo, M.; Kim, D.B.; Kim, J.; et al. In situ spectroscopic and computational studies on a $\mathrm{MnO}_{2}-\mathrm{CuO}$ catalyst for use in volatile organic compound decomposition. ACS Omega 2017, 2, 7424-7432. [CrossRef]

36. Perrichon, V.; Laachir, A.; Bergeret, G.; Frety, R.; Tournayan, L. Reduction of Cerias with Different Textures by Hydrogen and their Reoxidation by Oxygen. J. Chem. Soc. Faraday Trans. 1994, 90, 773-781. [CrossRef]

37. Santos, V.P.; Pereira, M.F.R. Catalytic oxidation of ethyl acetate over a cesium modified cryptomelane catalyst. Appl. Catal. B Environ. 2009, 88, 550-556. [CrossRef]

38. Wagner, C.D.; Naumkin, A.V.; Kraut-Vass, A.; Allison, J.W.; Powell, C.J.; Rumble, J.R., Jr. NIST Standard Reference Database 20. NIST XPS Database Version 2003, 3, 251-252.

39. Vepřek, S.; Cocke, D.L.; Kehl, S.; Oswald, H.R. Mechanism of the deactivation of Hopcalite catalysts studied by XPS, ISS, and other techniques. J. Catal. 1986, 100, 250-263. [CrossRef]

40. Shearer, G.C.; Chavan, S.; Bordiga, S.; Svelle, S.; Olsbye, U.; Lillerud, K.P. Defect Engineering: Tuning the Porosity and Composition of the Metal-Organic Framework UiO-66 via Modulated Synthesis. Chem. Mater. 2016, 28, 3749-3761. [CrossRef]

41. Ye, Z.; Giraudon, J.M.; Nuns, N.; Simon, P.; De Geyter, N.; Morent, R.; Lamonier, J.F. Influence of the preparation method on the activity of copper-manganese oxides for toluene total oxidation. Appl. Catal. $B$ Environ. 2018, 223, 154-166. [CrossRef]

42. Manuel, J.; Gilbank, A.L.; García, T.; Solsona, B.; Agouram, S.; Torrente-murciano, L. The prevalence of surface oxygen vacancies over the mobility of bulk oxygen in nanostructured ceria for the total toluene oxidation. Appl. Catal. B Environ. 2015, 174-175, 403-412.

43. Zhao, X.; Li, X.; Zhu, T.; Tang, X. Adsorption behavior of chloroform, carbon disulfide, and acetone on coconut shell-derived carbon: Experimental investigation, simulation, and model study. Environ. Sci. Pollut. Res. 2018, 25, 31219-31229. [CrossRef] [PubMed]

44. Ruthven, D.M. Principles of Adsorption and adsorption processes; John Wiley \& Sons: Hoboken, NJ, USA, 1984; p. 464.

45. Dey, S.; Dhal, G.C. Synthesis of Hopcalite catalysts by various methods for improved catalytic conversion of carbon monoxide. Mater. Sci. Energy Technol. 2020, 3, 377-389. [CrossRef]

46. Feng, X.; Hajek, J.; Jena, H.S.; Wang, G.; Veerapandian, S.K.P.; Morent, R.; De Geyter, N.; Leyssens, K.; Ho, A.E.J.; Meynen, V.; et al. Engineering a Highly Defective Stable UiO-66 with Tunable Lewis-Brønsted Acidity: The Role of the Hemilabile Linker. J. Am. Chem. Soc. 2020, 142, 3174-3183. [CrossRef] [PubMed]

47. Li, Y.; Gan, L.; Si, R. Effect of Tungsten Oxide on Ceria Nanorods to Support Copper Species as CO Oxidation Catalysts. J. Rare Earths 2019. [CrossRef]

(C) 2020 by the authors. Licensee MDPI, Basel, Switzerland. This article is an open access article distributed under the terms and conditions of the Creative Commons Attribution (CC BY) license (http://creativecommons.org/licenses/by/4.0/). 